\title{
ALGUNAS (OONSII)LRACIONL EN TORNO A LOS GOBIERNOS DE FACTO Y LAS VIGENCIAS
}

\section{CONSTITUCIONALES}

1. Presentación. 2. El tema del derecho a lá insurrección. 3. El Constitucionalismo y su crisis. 3.1. El Estado de Derecho y el Constitucionalismo. 3.2. Vigencias y mutuaciones constitucionales. 4. El problema de los gobiernos de facto. 4.1. Revolución, Golpe de Estado Y Funcionarios de Facto. 4.2. Efectos legales de los gobiernos de facto. 4.2.1. El ejercicio del poder constituyente. 4.2.2. Constitución y Estatuto de los gobiernos de facto. 4.2.3. Los Decretos Leyes. 4.2.4. La Jurisprudencia.

\section{Presentación.}

La vigencia de la Constitución durante gobier nos de facto, así como otros temas referidos en forma general a los efectos legales de este tipo de regímenes, han aparecido en forma polémica en el debate público en torno al Estatuto de Prensa $y$ a la expropiación de las empresas periodísticas (Decretos Leyes No. 20680 y 20681). (1).

Si bien el tema señalado no ha merecido especial interés para los juristas peruanos, últimamente ha venido aflorando en el debate público en circunstancias distintas. Como en este caso, ello ha ocurrido generalmente en función del debate de algún dispositivo legal que, en alguna forma, implicaba derechos o garantías declarados en nuestra Constitución de 1933.

En 1968, cuando el Gobierno Revolucionario de la Fuerza Armada accedió al poder, el artículo 50. del Estatuto Revolucionario (Decreto Ley No. 17063) señaló que: "El Gobierno Revolucionario actuará conforme a las disposiciones del presente Estâtuto y a la Constitución del Estado, Leyes y demás disposiciones en cuanto sean compatibles con los objetivos del Gobierno Revolucionario". Era la primera vez que en el Perú, un gobierno de facto re- ducía expresamente $y$ en un texto legal, a la Constitución a un rol supletorio. Desde entonces, la aplicación explícita o implícita de este artículo y la invocación del carácter revolucionario del gobierno, han fundado muchas acciones, señalándose para ello, la vigencia del Estatuto Revolucionario por encima de la Constitución, aşi como la existencia de un verdadero periodo constituyente destinado a crear un nuevo orden jurídico $y$ constitucional.

La doctrina constitucional, se ha ocupado desde hace mucho del fenómeno de las revoluciones y los golpes de Estado, no sólo en cuanto la transgresión de normas vigentes que implica su arribo al poder, sino estudiando principalmente los problemas derivados de los efectos que producen en el ordenamiento jurídico, considerando que los gobiernos de facto generalmente son creadores de derecho por virtud de si mismos y no por cualificación del ordenamiento vigente $(2)$.

(1) Entre los diversos artículos periodísticos cabe resaltar los siguientes: BUSTAMANTE Y RIVERO, José Luis: El Estatuto de Prensa y otros temas, en CARETAS, No. 502. Lima, 28 de agosto de 1974, p. 10. CORNEJO CHAVEZ, Héctor: Revolución y Derecho, en EL COMERCIO, Lima, 8 de setiembre de 1974, PEÑALOZA RAMELLA, Walter: El pronunciamiento del Dr. Bustamante y Rivero (serie de seis articulos), en LA PRENSA, Lima, del 8 al 14 de setiembre de 1974, BONET, José Luis: ¿Constitución a estas horas? en LA CRONICA, Lima, 14 de setiembre de 1974. BUSTAMANTE Y RIVERO, José Luis: Bustamante replica a Cornejo, en CARETAS, No. 504, Lima, 8 de octubre de 1974, p. 25.

(2) Un análisis de esta problemática y la presentación de diferentes puntos de vista acerca del tema, puede encontrarse en: CATTANEO, Mario: El Concepto de Revolución en la Ciencia del Derecho. Buenos Aires, Ediciones Depalma. 1968. 
Tales gobiernos plieden significar únicamente una sustitución de funcionarios, pero pueden implicar también un verdadero cambio de principios ordenadores del Estado, de las bases mismas del derecho que rige a la comunidad, de modo que la legalidad futura se asiente sobre bases muy distintas a la legalidad precedente.

Sin embargo, no encontramos en el Perú una preocupación por esta problemática que conduzca a su estudio jurídico. Una revisión de la bibliografía y de las principales publicaciones especializadas, nos demuestra que a pesar de la frecuencia histórica con la que han llegado al poder gobiernos en una forma no prevista por el ordenamiento jurídico vigente, el tema de los gobiernos de facto se ha mantenido fuera del ámbito de estudio del derecho. Los trabajos sobre la materia que ofrecen mayor interés, son aquellos que se han ocupado de este problema desde otras perspectivas (3).

Para explicar lo señalado, es pertinente precisar cuál ha sido la actitud predominante en los profesionales del derecho, ante la presencia de gobiernos de facto. Asimismo, resulta fundamental analizar el verdadero carácter de ellos -simple golpe o revolución- pará entender el análisis jurídico que ha merecido. En esta presentación, detengámonos en el primer asunto.

Revisando las principales publicaciones jurídicas de los últimos veinticinco años, encontramos que conjuntamente con una actitud sacralizadora de la Constitución, vinculada con las características de la ideología jurídica predominante, ha existido, contradictoriamente, una adecuación casi indiferente a los gobiernos de facto (4).

Generalmente se ha considerado a estos gobiernos como etapas de paréntesis constitucional, que pronto serían superadas por el retorno del "imperio de la constitucionalidad", sin que aparentemente preocupara la reiteráción del fenómeno y su vinculación con otros prublemas de vigencia constitucional.

Haciendo una revisión de los pronunciamientos de los Colegios de Abogados, con el propósito de detectar su actitud, tenemos que el Colegio de Abogados de Lima se pronunció en 1962 como en 1968 condenando los golpes de Estado. En 1948 no hubo pronunciamiento alguno, siendo de destacar que en la primera sesión de Mesa Directiva realizada después del golpe del General Odría, el tema ni siquiera fue tratado (5).

94
En 1962, el Colegio de abogados fijando su posición ante "la quiebra del orden constitucional en el pais y la instauración de un gobierno de facto", declaró:

“2) Tal realidad hace imperativo retornar al régimen de legalidad por la única vía democrática: la consulta a la voluntad popular, fuente de soberanía, mediante el voto libre y auténtico.

“3) En presencia de la situación producida corresponde al foro propugnar el más pronto restablecimiento de las garantías constitucionales y la realización de elecciones generales, en plazo improrrogable bajo normas in tachables" (6).

Consideramos que el contenido de este Comunicado, sintetiza la actitud tradicional frente al fenómeno de los gobiernos de facto, reiterada en octubre de 1968:

"El Colegio reclama a quienes han asumido la responsabilidad del poder, el pronto retorno a la constitucionalidad, por medio de un proceso electoral, libre y democrático, sin ninguna discriminación, pues ésta es la única forma jurídicamente aceptada para solucionar los trascendentales problemas de la República" (7).

(3) En ese sentido, deben destacarse los trabajos de Victor VILLANUEVA: La tragedia de un pueblo y un partido Lima, Gráficos Victory, 1956: El Militarismo en el Perí Lima, Emp. Gráfica Scheuch, 1962. Un año bajo el sablé. Lima. Emp. Gráfća Scheuch, 1963. ¿Nueva Mentalidad Mili. tar en el Perí? Ed. Mejia Baca, 1969, I00 Años del Ejér, (1) Peruano: Fnustraciones y Cambios, Lima, Ed. Juan Me jía Baca, 1972. EL CAEM y la Revolución de la Fuerzu Armada: Lima, Inst. de Estudios Peruanos, 1972. Ejército peruano: del caudillaje anárquico al militarismo reformista Lima, Ed. Mejía Baca, 1973.

(4) Sobre esta actitud a propósito del golpe de Estado de 1962, Ilama la atención el sociólogo francésFrancois Bourricaud: Poder y Sociedad en el Perú Contemporáneo. Buenos Aires, SUR Ed., 1967; p. 310 y sig.

(5) Sesiones de Mesa Directiva. En: Revista del Foro, No. 7.12, año 1948; p. 216.

(6) Declaración de la Junta Directiva del Colegio de Abogados de Lima con motivo de la instauración del Gobiemo de Facto. En: Revista del Foro, año XLIX, 1962, No. 2 y 3 (7) Comumicado del Colegio de Abogados de Lima con mo. tivo del cambio de facto en el régimen de gobierno. En Revista del Foro, 1968, No. 2-3; p. 172. 
Similar actitud hemos encontrado tradicionalmente en el Poder Judicial. No existen declaraciones generales -al estilo de las "Acordadas" de la corte Suprema Argentina - ni una verdadera doctrina jurisprudencial, como existe en otros países (8). Generalmente, se ha considerado que este problema no era materia que incumbiera al Poder Judicial.

"El día jueves 3 de octubre del año pasado, el gobierno constitucional fue reemplazado por una Junta Revolucionaria de Gobierno. Como hombres de derecho lamentamos profundamente este quebrantamiento grave del orden constitucional, que de nuevo nos coloca a la espera de elcciones libres para devolver al pueblo el derecho inalienable de elegir sus gobernantes.

Este hecho ha servido para el Supremo Tribunal reafirme una vez más su independencia con relación al quehacer político. . La Constitución no confiere a la Corte Suprema la facultad de reconocer a los gobiernos de facto por lo que en respuesta al oficio del Señor Ministro de Justicia en que comunicaba la constitución de un nuevo gobierno, la Corte expresó su deseo de seguir actuando dentro del marco de sus actividades jurisdiccionales, contribuyendo así al imperio del derecho en el Perú" (9).

No obstante, es preciso que en los últimos seis años, la actitud de los profesionales de derecho frente a los gobiernos de facto (10), ha sufrido algunos cambios importantes. Sin duda ello se debe a las características particulares del Gobierno Revolucionario de la Fuerza Armada instaurado en 1968, que ha hecho que la problemática de los gobiernos de facto se plantee a un nivel distinto, que va más allá de la simple expectativa de un "retorno a la constitucionalidad". En ese sentido, resulta significativa la última Memoria del Presidente de la Corte Suprema, tanto por sus consideraciones acerca del actual gobierno de facto, como por el pronunciamiento que implica acerca del rol del Derecho y la vigencia de la Constitución:

"Entonces, si el derecho viene a ser la realidad en acción y el ideal es siempre obtener la justicia, ésta debe primar en todo caso sobre aquél y establecerse por las vías de la interpretación jurisprudencial a fin de lograr el sano equilibrio que debe normar la relación socio-jurídica ac- tual, por ser fuente indiscutible del derecho, porque en el momento histórico que vivimos, según el Estatuto que nos rige ninguna ley puede ser incompatible con los altos fines de la Revolución, ni la misma Constitución, que sólo queda vigente en cuanto sus disposiciones se compatibilicen y sirvan de anexo o entroncamiento a la concreción de sus fines. El fin inobjetable es la obtención de la justicia, y la justicia social y económica, aún sobre el derecho, pues ésta como acabo de decirlo, no puede servir para amparar la injusticia ni la alteración del orden en ningún caso.

El problema actual entonces, se torna en uno de adaptación $\mathrm{e}$ interpretación de la norma vigente frente a la realidad nacional, y esa labor corresponde al Poder Judicial renovado, con el nuevo espiritu que está animando la América y a nuestro Perú en forma particular.

Acabamos de constatar que por las vías de la verdadera interpretación jurisprudencial se están poniendo en plena vigencia jurídica principios estructurales y filosofía que contiene el Estatuto Revolucionario que nos rige" (11).

Se trata del reconocimiento expreso de la revolución como fuente de derecho y del actual Estatuto Revolucionario como norma fundamental.

Considero de interés resaltar en esta presentación, algo que resulta particularmente significativo, no sólo para deslindar las características del actual gobierno de facto, sino para interpretar actitudes asumidas frente a él; se trata de las oportunidades

(8) BELAUNDE, Javier de... El Problema de los Gobiernos de Facto en Argentina y Perí. Lima, Tesis de Bachiller en Derecho, PUC, 1971

(9) GARCIA RADA, Domingo. . Memoria leida en la ceremonia de apertura del Año Judicial de 1969. En: Memorias $\checkmark$ discursos en las ceremonias de apertura del año fudicial de $1969 ;$ p. 5 .

(10) Este término lo venimos usando por ahora en general, para designar a los gobiernos que han llegado al poder por una imposición de hecho, al margen de la forma prevista por el ordenamiento vigente.

(11) GARCIA SALAZAR, José. . Memoria del Presidente de la Corte Suprema En: EL PERUANO, Lima, 19 de marzo de 1974. 
en que se ha objetado por inconstitucional ya sea el gobierno mismo o las medidas legislativas adoptadas por él. Si bien es exacto que en 1968 se produce la misma adecuación casi indiferente a la anteriormente anotada por Bourriçaud, no lo es menos que a partir de entonces hasta la fecha, se han sucedido, en diversas oportunidades, objeciones de indole constitucional al actual gobierno de facto. Conviene precisar el ca. rácter de tales objeciones y las circunstancias que las motivan.

Resulta de interés la actitud asumida por el Colegio de Abogados de Lima a partir de enero de 1973, asi como las coyunturas políticas en las cuales se ha planteado en los últimos años el tema de la vigencia de la Constitución en un gobierno de facto y el tema de la revolución en el derecho.

Una revisión cronológica desde 1968 (12) nos demuestra que dichos temas han sido pocas veces analizados desde un ángulo jurídico (13) y que cuando ésto se ha hecho, la mayoría de las veces -como ya señalamos-, el debate se ha orientado en torno a la constitucionalidad o inconstitucionalidad de algún dispositivo legal que se trataba de cuestionar.

En 1968, después de que asumió el poder el Gobierno Revolucionario de la Fuerza Armada, el tema de la violación del ordenamiento jurídico cons. titucional se planteó en la forma ya descrita, y es desde esa perspectiva que, inclusive el mismo Gobierno trató de fundamentar su acceso al poder como un cumplimiento de un deber constitucional.

\footnotetext{
"Tanto el gobierno como el parlamento incumplieron la Constitución. Por eso, ante la conciencia más exigente, el advenimiento del Gobierno Revolucionario fue un imperativo que nuestros mayores habian grabado como mandamiento supremo en el artículo 213 que ordena a la Fuerza Armada "asegurar el cumplimiento de la Constitución y las leyes" (14).
}

En enero de 1970 aparece por primera vez en debate el tema de la vigencia de la Constitución. La circunstancia que lo motivó fue la promulgación del Decreto Ley No. 18075, Estatuto de la Libertad de Prensa, el cual fue cuestionado por su inadecuación a la Constitución. En esa línea, el Decano del Colegio de Abogados de Lima presentó un Recurso de
Habeas Corpus pidiendo la derogatoria del referido Estatuto. Lo propio hicieron la Asociación Nacional y la Federación de Periodistas. El debate público y político se organizó en torno al Estatuto $y$ a la vigencia de las garantías democráticas consagradas en la Constitución de 1933. La respuesta que dio el Gobierno entonces a los ataques contra la ley de Prensa, se dirigió a defender su constitucionalidad y su adecuación al ordenamiento legal vigente, en tanto implicaba una reglamentación del art. 63 de la Constitución (15).

El tema de la vigencia de la Carta de 1933, reapareció posteriormente en diversas oportunidades. En algunos casos para pedir la redacción de una nueva Constitución (16), usando del anuncio del Presidente Velasco en su Mensaje a la Nación de julio de 1969 (17), y en otros casos, para pedir la vuelta a la vigencia de la Constitución (18).

La promulgación de dos Decretos Leyes nuevamente motivó el debate en torno al tema que nos ocupa. El Decreto Ley No. 18896 que creó el Sistema Nacional de Apoyo a la Movilización Social (19) de junio de 1971 y el Decreto Ley No. 19020 de noviembre de 1971 que dispuso que las acciones de las empresas de radio y televisión eran susceptibles de expropiación (20).

(12) Se toma como referencia: PEASE GARCIA, Henry $y$ VERME INSUA, OIga... PERU 1968-1973, Cronología politica. Lima, DESCO, 1974.

(13) En este sentido ofrece especial interés la Memoria que como Presidente del Consejo Nacional de Justicia presentó el Dr. Héctor Cornejo Chávez; Derecho y Revolución, Lima, Oficina Nacional de Información, 1971.

(14) VELASCO, Juan... Discurso pronunciado en la División Blindada el 7 de noviembre de 1968. En: VELASCO, la voz de la Revolución, Lima, Ediciones Peisa, 1970; p. 9. (15) Comunicado Oficial. En: PEASE GARCIA, Henry y VERME INSUA, Olga ... op. cit. Tomo I, p. 135, hecho No. 617.

(16) Ibidem, Tomo 1, p. 226, hecho 965.

(17) VELASCO, Juan... Mensaje a la Nación, 28 de Julio de 1969. En: VELASCO, la voz de la Revolución, p. 55.

(18) PEASE GARCIA, Henry Y VERME INSUA, Olga... op. cit.; Tomo 1, p. 242, hecho 1023; p. 243, hecho 1030; p. 244; hecho 1032 .

(19) Ibidem, Tomo I, p. 299, hecho 1298.

(20) Ibidem, Tomo 1, p. 335, hecho 1451. 
Sin embargo, fue en 1973 durante el quinto año del Gobierno Revolucionario, cuando se promovió con una mayor intensidad el debate en torno al tema constitucional. Las circunstancias fueron variadas, pero resulta interesante resaltar que en la mayoría de ellas encontramos a la Mesa Directiva de Colegio de Abogados de Lima, ya sea cuestionando por inconstitucional alguna medida del Gobierno, o reclamando en general la vuelta a la constitucionalidad. En ese sentido destaca el Discurso del Decano, Dr. Vicente Ugarte del Pino en el homenaje que se ofreciera al Presidente de la Sociedad Nacional de Industrias y el discurso del Dr. Luis Felipe Villarán Freire en el acto organizado para conmemorar los 40 años de la Constitución de 1933 (21).

Ese año se publicó el Ante-Proyecto de Ley sobre Empresas de Propiedad Social para su debate público, el cual, concitó el interés $y$ análisis de diversas organizaciones. En esa oportunidad encontramos también, respecto de tal proyecto, el cuestionamiento en razón de su incongruencia con la Constitución. No sólo se debatió el contenido mismo del proyecto y el nuevo sistema de empresas que se proponía crear, sino su concordancia o no con el derecho de propiedad consagrado en la Carta de 1933. Así, la crítica que realizó el Colegio de Abogados de Lima desde esta perspectiva, no sólo comprendía la denuncia de la presunta inconstitucionalidad de este proyecto, sino, yendo más allá, señaló que "el proyectado Decreto Ley, constituye un dispositivo incompatible con los postulados constitucionales y legales y así como con los principios éticos, filosóficos y religiosos que conforman la cultura peruana de histórica vocación occidental y cristiana...". acordando, "Dejar constancia de su protesta por pretender cambiar el sistema jurídico peruano al margen de las instituciones y procedimientos señalados por la Constitución del Estado" (22). Otros pronunciamientos llegan a sostener que dado que dicho proyecto implica un sustancial cambio del sistema de propiedad que rige a la República, hace falta para la sanción de la nueva ley, una Asamblea Constituyente (23).

Como indicamos en las primeras líneas, el debate en torno al reciente Estatuto de Prensa, promul. gado en julio de 1974 ha puesto nuevamente sobre el tapete el tema de la vigencia de la Constitución de 1933. En esta oportunidad la respuesta que recibe una argumentación basada en la inconstitucionali- dad del dispositivo, es distinta a las anteriores. No se trata de demostrar con igual racionalidad su constitucionalidad. Se postula simple y llanamente el carácter supletorio de la Constitución frente al Estatuto Revolucionario y se esgrime como razón fundamental, que el Perú vive una revolución, que por tanto no puede estar condicionada por la norma fundamental que respondía a los valores $y$ a un estado de cosas anterior.

"En suma, el Estatuto traduce un esfuerzo por respetar al máximo posible las normas de la Constitución de 1933. Se puede estar o no de acuerdo con ésto. Personalmente, creo que no se puede hacer una revolución dentro de los marcos de la Constitucionalidad. Por la sencilla razón de que ésta consagra lo fundamental del orden social, económico y político que precisamente la revolución tiene que cambiar... porque, si no lo cambia, no es revolución.

Pero incluso para quienes, como el Gobierno actual, piensan que la revolución puede marchar hasta cierto punto del camino sin derogar toda la Constitución, el acatamiento de ella tiene, necesariamente, un límite: el que marcan los objetivos esenciales de la propia revolución, aquellos que justifican su propia existencia. Porque pedirle a una revolución -cualquiera que ella sea, siempre que sea verdadera- que se sujete a la vieja Constitución es, no sólo pedirle que renuncie a ser revolución, es decir, que se suicide, sino esperar de ella el milagro, que jamás podrá hacer hombre alguno, de demoler un orden robusteciéndolo, de lograr la justicia manteniendo la injusticia, de cambiar el futuro sin modificar el presente.

$Y$ es a ésto que responde el artículo 5o. del Estatuto del Gobierno Revolucionario, según el

(21) Ibidem, T. I1, p. 469, hecho 1947; p. 475, hecho 1967; p. 508, hecho 2157 y p. 557, hecho 2168.

(22) Ibidem, T. I1, p. 608. Comunicado emitido por la Mesa Directiva del Colegio de Abogados de Lima.

Complementa este pronunciamiento, en la misma línea argumentativa, el elaborado por el Dr. Julio Vargas Prada, V emitido por el mismo Colegio de Abogados, del que da cuenta el hecho No. 2283, p. 610 de la Cronología Polf́tica que citamos.

(23) Ibidem, T. II, p. 639, hecho 2339. 
cual no está en vigencia la Constitución promulgada hace 41 años en cuanto se oponga a los objetivo de la revolución" (24).

Como se ve en las líneas que anteceden, de una cierta indiferencia por el problema de los gobiemos de facto, se ha pasado en los últimos años, a un planteamiento reiterado de aspectus fundamentales de este fenómeno. Ello no es casual.

Hemos visto también, cómo las coyunturas en que estos problemas se han agitado, han sido siempre coyunturas de significado político. Ha sido frecuente la contraposición entre la vigenciá de lá Constitución y la promulgación de tal o cual Decreto Ley. Ello nos estaría demostrando que la preocupación constitucionalista, no se ha dado por el problema en si mismo, sino implicada en medidas de significación económica y política, que fueron er? verdad los centros de la preocupación.

Como veremos en las líneas siguientes, ello st debe a las características pecualiares del Gobierno Revolucionario de la Fuerza Armada que, sin duda, constituye un gobierno de facto distinto a los anteriormente habidos en el Perú. El art. 50. del Estatuto Revolucionario ya lo anunciaba $y$ su reiterada invocación ante medidas concretas lo han corroborado.

Esta problemática, la de los gobiernos de facto $y$ sus efectos en el sistema jurídico, debe ser analizada en un cuadro más amplio, el de las vigencias constitucionales en la consideración global de la crisis del constitucionalismo.

Por ello, en los párrafos siguientes, nos interesa analizar suscintamente dos aspectos fundamentales: la consideración jurídica que se ha dado a los gobiernos de facto $y$ el problema de las vigencias $y$ mutuaciones constitucionales. Nos interesa en este aspecto constatar, no sólo durante los gobiernos da facto, sino en épocas de vigencia formal de la Constitución, la existencia de prácticas constitucionales diversas que pueden llegar a crear lo que se podría denominar una Constitución reál paralela, distinta $y$ hasta contrapuesta a la formalmente vigente que, como Ley Fundamental del Estado, se supone que otorga a todo el sistema legal, coherencia de significado.

\section{El tema del derecho a la insurrección.}

98
Hemos señalado que el tema de la revolución y el derecho es antiguo en la doctrina jurídica. Sin embargo, los enfoques han variado de acuerdo a las circunstancias históricas y a las corrientes del pensa. miento jurídico. Durante mucho tiempo su estudio - fue el estudio del derecino a la insurrección dentro de una perspectiva eminentemente moral, planteando la existencia de un derecho a la insurrección, o de un derecho del pueblo de resistencia contra el poder político, es decir, contra quien detentando la auturidad, incumpliera las obligaciones impuestas por el pacto social deviniendo en déspota o tirano.

Señala Sánchez Viamonte que, "el derecho de resistencia a la opresión es el derecho que tiene toda sociedad de hombres dignos y libres para defenderse contra el despotismo, e incluso destruirlo... El derecho de resistencia a la opresión se puede identificar con la defensa del derecho en abstracto, en su condición de principio ético-político... No tiene por sujeto al individuo sino a lá colectividad o comunidad que, con el nombre del pueblo (demos), constituye una entidad moral..." (25).

Linares Quintana sintetizando la concepción sobre este derecho moral y político, sostiene que, “teóricamente la revolución se presenta como la antitesis del gobierno constitucional; pero no puede negarse a ningún pueblo el esencial derecho de rebelarse contra el despotismo y la tiranía, ya que en tal caso precjsamente, la revolución aparece como el medio capaz de operar la constitucionalización del Estado desconstitucionalizado" (26).

Este tema no ha estado del todo ausente en el Perú, ya que lo encontramos planteado por nuestros constitucionalistas. Raúl Ferrero lo hace en relación a la ley injusta y contra el gobierno tiránico, como un derecho comúnmente aceptado para ser ejercido por la colectividad: "El derecho de resistencia es invocado por las comunidades tiranizadas, al modo como el estado de necesidad es invocado por el Po-

(24) CORNEJO CHAVEZ, Héctor... Revolución y Derecho, En: EL COMERCIO, Lima, 8 de setiembre de 1974. (25) SANCHEZ VIAMONTE, Carlos... Revolución y Docirina de Facto. Buenos Aires, Impresora La Plata, 1946; p 38.

(26) LINARES OUINTANA, Segundo... Tratado de la Ciencia del Derecho Constitucional. Buenos Aires, Editorial Alfa, 1956, T. VI; p. 248 
der. Son recursos empleados en casos de verdadera excepcionalidad y fuera de la estabilidad calculable que el orden jurídico supone", puntualizando que "comporta una cuestión de doctrina moral o sicológica, antes que un problema de indole jurídico", ya que "toda revolución encuentra su justificación o condena más en la Historia que en el Derecho" (27).

La formulación del derecho a la insurrección tiene un origen muy antiguo, como lo señala Cattaneo (28). Formulado ya por los griegos en la forma del tiranicidio fue sometido a desarrollo y elaboración en una teoría completa por obra de la doctrina jusnaturalista católica medieval. Posteriormente, en los siglos XVII y XVIII, fue adoptada por los jusnaturalistas liberales como un derecho del pueblo ante el incumplimiento del soberano, teniendo su consagración en la Revolución Francesa, donde fue enunciado como derecho del hombre en las Declaraciones de 1789 y 1973. Este postulado lo encontramos también formulado en 1776 en la Declaración de Derechos del Esatado de Virginia.

De esta manera, se torna una institución de derecho público, ante la necesidad de dar una formulación jurídica a un postulado político oponible al absolutismo. Pero el posterior desarrollo de las doctrinas políticas liberales, obligó prácticamente a la anulación de este principio, dando paso a la jurisdicción constitucional, ya que el enunciado del derecho a la insurrección se tornaba peligroso ante el desarrollo del Ilamado Estado de Derecho. La jurisdicción constitucional aparece como "una tutela creada en favor de los ciudadanos contra los actos. réalizados en violación de la Constitución. . extremo del proceso de absorción y sustitución del derecho de resistencia en las estructuras del Estado de Derecho" (29).

El estudio del derecho a la insurrección, como el estudio de la revolución corresponde, según precisa Cattaneo, a las corrientes jusnaturalistas, habiéndose desplazado el interés de los juristas hacia el estudio de la revolución en su acontecer efectivo, con el paso del jusnaturalismo al positivismo jurídico en la historia de la filosofía del derecho.

En Latinoamérica la invocación y formulación de este principio se da desde la etapa previa a la Emancipación. No sólo aparece en muchos casos co- mo sustento de insurrecciones producidas, sino que su perspectiva orienta el estudio del fenómeno de las revoluciones, hasta épocas muy recientes.

Así, en la última década, el constitucionalista argentino Bidart Campos invoca este principio en la realidad presente de los paises Latinoamericanos. Refiriéndose concretamente al caso argentino en 1966, cuando se acababa de producir el acceso al poder de las Fuerzas Armadas, reflexiona contra un estado de caos político y social; contra un gobierno que frustrando las esperanzas de las mayorías había frustrado el logro del bien común. Tratando de justificar la intervención militar, Bidart nos lleva más allá, al terreno de la justificación jurídica de la insurrección, ya no sólo contra la tiranía política, sino contra la opresión económica y social.

\begin{abstract}
"Pero a poco que se ahonde en el tema, tal ve" los mismos principios suarecianos nos permiter extender un igual derecho de resistencia a otrosupuestos. Firano es quien gobierna contra la ley natural, o contra di bien común, periudicando a la comunidad. Si la tirania como reverso de la justicia nos hace pensar en un gobernante y en un régimen opresores de la libertad y los derechos del hombre, ¿qué calificativos reservamos para el gobierno y el régimen que, sin incurrir en esa opresión frustran el bien común? (30).
\end{abstract}

"El mensaje de las fuerzas armadas, en un análisis desapasionado, ha hecho alusión a un vacio de autoridad y un espectáculo de anarquía en el escenario de un orden social elemental inexistente. Casi no parece discutible la realidad de ese panorama. El desquiciamiento de nuestrotégimen político implicaba la ruptura del equilibrio impreseindible entre la autoridad y la libertad: la libertad no había sido destruida, pero la autoridad sí. El bien común no es accesible en tales circunstancias. Eso sólo proporciona causa de justificación a la resistencia activa, cuando

(27) FerRero Rebagliatl, Raúl... Teoría del Estado. Lima, Ediciones Studium, 1966; pp. 262-263.

(28) CATTANEO, Mario. . op. cit.; p. 9 y sigs.

(29) Ibidem, p. 13

(30) BIDART CAMPOS, Germán.. Derecho Constitucional, Buenos Aires, Talteres Gráficos Julio Kaufman, S.R.L. Ediar, 1966, T. 11; pp. 645-646. 
los recursos normales han quedado obstruidos. $Y$ nadie puede pensar que en el clima vigente hasta el 28 de junio, fuera viable un cambio total de la situación a través de los resortes comunes. La salida electoral, por de pronto, obscurecía toda perspectiva próxima de clarificarla. La espera, lejos de proporcionar remedio, estaba llamada a agravar el mal, tornándolo tal vez en incurable. Por paradoja, pues, un movimiento de fuerza ha hallado título válido en una situación que, lejos de tipificar una tiranía, era casi lo contrario, un régimen donde la debilidad irremediable del poder mostraba la ausencia de autoridad suficiente" (31).

La sustentación en América Latina de este principio, ha llegado lejos, incluso al intentu de formu. larlo legislativamente. Sin embargo, las dificultades son manifiestas, ya que aparece contradictorio que un ordenamiento jurídico -que exige coercitivamente su obediencia- pueda preveer su destrucción o violación. Estos problemas se hicieron evidentes en 1948, cuando Cuba propuso en la Conferencia Interamericana de Bogotá la adopción de una fórmula legislativa que reconociera el derecho de resistencia contra la opresión. Propuesta que en razón de tales dificultades, no fue acogida (32).

A través de una brevísima revisión histórica, vemos que en el Perú en el siglo $X X$ se ha esgrimido en más de una oportunidad en forma pecualiar, el ejercicio del derecho a la insurrección, con el propósito de intentar una justificación a la instauración de gobiernos de facto. Si bien no pretendemos un análisis histórico de las causas de ellos, considero oportuna esta breve referencia, la que no sólo nos sirve para establecer, en cuanto a los efectos sobre el ordenamiento, el carácter del gobierno de facto, sino que nos muestra una característica de la ideología jurídica que ha predominado: la sacralización del texto constitucional. Vemos, como en casi todos los casos quienes han insurgido y llegado al poder tratan de justificar su insurrección en el propósito de salvaguardar valores fundamentales, muchas veces se trata de probar la defensa de la vigencia de la Constitución misma, manteniendo asi la actitud que anotábamos.

Si bien en 1930, cuando el Teniente Coronel Sánchez Cerro se levantó contra Leguía, es la única vez que se esgrime explícitamente el derecho de resistencia contra la tiranía (33) existen otras circuns- tancias en las que la defensa de valores superiores o -como diría Linares Quintana- "la constitucionalización el estado descontitucionalizado", son presentadas como justificación de la insurrección.

En 1914, 1919, y 1962 hay valores constitucionales cuya salvaguarda se invoca. Tal es el caso de la rebelión encabezada por el Coronel Oscar R. Benavides que triunfó en 1914 derrocando al Presidente Billinghurst, quien había anunaciado "un gobierno del pueblo para el pueblo" e intentaba poner en marcha un avanzado programa de reformas sociales. Billinghurst se proponia disolver el Parlamento opositor y convocar al pueblo para que se pronunciara sobre un nuevo Congreso y una nueva Constitución, todo ésto al margen del ordenamiento vigente. EI triunfo de la insurrección militar fue saludado por el Congreso y por la Corte Suprema.

"El Tribunal se congratula, con la efusión del más sincero patriotismo, de que en breves instantes haya desaparecido la alarma de la República que veía en peligro sus instituciones y la paz interior; y esperan de la ilustración y civismo de los Ministros que componen la Exa. Junta, que cooperarán eficazmente a que se consoliden el respecto a la Constitución y el imperio de las leyes" (34).

Los golpes de 1919 y 1962 intentan -según lo postulan- salvar el derecho al sufragio. El primero para hacer respetar el veredicto popular -después del triunfo en las urnas de Leguía- y el segundo para posibilitarlo, en las postrimerías del segundo gobierno de Prado.

En la autotitulada "revolución Restauradora" de 1948, también hubo la invocación de la defensa de valores de ese orden, ya que -según lo señaló su Manifiesto y su Estatuto- "frente a la situación de

(31) Ibidem, p. 696.

(32) Anuario Jurídico Interamericano. Pan American Union, Washington, 1953; pp. 380-1. En: LINARES QUINTANA, Segundo. .. op. cit. T. VI; pp. 314-315.

(33) Ver "Manifiesto de Arequipa". En: GARCIA BE. LAUNDE, Domingo. . E El Constitucionalismo peruano $y$ sus problemas. Lima, materiales de enseñanza PUC, 1970; p. 4.1.6. a.

(34) BASADRE, Jorge. . Historia de la República del Peni, Lima, Talleres Gráficos Villanueva, 1962, quinta edición, $T$. VIII; p. 3750. 
desquiciamiento nacional y zozobra pública" (35), pretendía "restablecer el régimen democrático y mantener el orden y tranquilidad tan hondamente quebrantados por el régimen derrocado" (36).

En 1968, este tipo de argumentación también se presenta, pero dentro de un contexto de razones justificatorias muy diverso (Supra, cita 14).

El gobierno institucional de la Fuerza Armada, formulada desde el inicio su vocación de permanencia, a través del anuncio de su acceso al poder para iniciar un proceso de transformaciones estructurales. No intenta justificar su presencia, como en otros casos, en términos de una situación transitoria, de "paréntesis constitucional" para un "pronto retorno a la Constitucionalidad", sino en términos de asumir con las funciones de gobierno una responsabilidad histórica: romper con un orden social y económicc denunciado como injusto $y$ crear uno nuevo. Ello implica un programa de gobierno $y$ una continuidad en el poder. En esa línea el Estatuto Revolucionario es eregido como ley fundamental.

\section{El Constitucionalismo y su crisis.}

\subsection{Estado de Dereciıo y Constitucionalismo.}

En estas líneas no pretendemos ni un análisis riguroso ni una descripción detallada, solamente in. tentamos presentar una visión general de conceptos tales como Estado de Derecho y Constitucionalismo. Ello lo hacemos sólo dentro de la perspectiva del trabajo, ya que queremos poner de relieve algunos aspectos que nos permitirán luego plantear el problema de las vigencias y mutaciones constitucionales, y el problema de los gobiernos de facto $y$ sus efectos normativos.

Se ha definido al Estado de Derecho "como aquel conformado sobre la idea de libertad, o sea, que ha organizado los poderes en forma que se contrapesen recíprocamente, mirando como objetivo último del Estado la seguridad de la persona y li vigencia de un orden jurídico que permita a cadi hombre realizar su destino" (37).

La formulación del Estado de Derecho se encuentra vinculada en su origen y desarrollo al Esta. do liberal. Aunque sus bases doctrinarias sean ante riores, su origen está en la Revolución Francesa. La naciente burguesía liberal que esgrimió contra el Antiguo Régimen el derecho de resistencia, al triunfar históricamente tratá de formular un ordenamiento jurídico, un cauce, por donde transcurra regladamente la vida del Estado, diseñando un sistema perfeccionado de garantias.

Surge coronando esta concepción, el constitucionalismo, como un sistema destinado a institucionalizar la vida jurídica de un país mediante un conjunto coherente de normas impuestas a gobernantes $y$ a gobernados. El propósito de garantía y de seguridad perseguido por la ideología liberal encuentra asi una estructuración legal, en cuya cúspide está una norma fundamental que le da coherencia: la Constitución escrita, que juridiza el ejercicio del poder del Estado que, al mismo tiempo, se autolimita en función de la seguridad.

Muchos autores han denominado a esta concepción, el "constitucionalismo clásico", el cual "con posterioridad a la revolución francesa... cobra carta de ciudadanía, permitiendo decir a Adolfo Posada que la expansión del mismo, como movimiento jurídico $y$ político sólo tiene similitud con la difusión del derecho romano" (38).

La influencia de estos planteamientos se presenta muy claramente en América Latina en el nacimiento de las nuevas Repúblicas en el siglo XIX. Las ideas de libertad e independencia, encuentran una formulación orgánica en los planteamientos liberales y las primeras Constituciones - verdaderas actas de nacimiento $y$ programas de existencia- van a ser el fiel reflejo de ellas.

Asi, el derecho colıstitucional hispanoamericano -desde sus orígenes- se impregna de liberalismo, asignando a la Constitución como contenido indispensable la tutela de la libertad y de la seguridad individuales. Asimismo, se diseña un tipo ideal de Estado Constitucional, haciendo absoluta abstracción de la realidad.

Esta concepción del constitucionalismo $\mathrm{v}$ del

(35) Manifiesto, en: VILLANUEVA, Victor... El Militarismo en el Perú; p. 123.

(36) Estatuto de la Junta Militar de 1948. D.L. 10889.

(37) FERRERO, Raúl, op. cit., p. 199.

(38) BIDART CAMPOS, Germán... op. cit., T.l.: I', to. 
Estado de Derecho es la que perdura por muchos años, siendo modernizada y adecuada a las circuns. tancias particulares en sucesivas Constituyentes. Podemos afirmar, sin temor a una generalización excesiva, que en todas las Constituciones que ha tenido el Perú los postulados y supuestos del Constitucionalismo clásico han inspirado a ellas, no sólo en la estructuración básica del aparato estatál, sino en la formulación del sistema de garantías.

Conviene puntualizar brevemente las características principales de esta concepción. Diversos autores las han señalado. Nosotros utilizando tales tipificaciones queremos resaltar los siguiente:

A) El objetivo del Estado de Derecho se centra en la obtención de una suficiente garantía y seguridad juridica para los derechos individuales.

A.1). Así, la Constitución aparece como una ley de garantía para el individuo frente al Estado. Por ello, resulta fundamental que ésta contenga una de. claración, casi un listado, de derechos individuales. "La declaración de derechos se hace parte necesaria de la constitución, porque su sola exposición importa su realización efectiva. . Vaciado de todo contenido histórico, el molde de estas declaraciones se caracteriza por su abstracción, a-historicidad, su elaboración racionalista y a-priorística. Los derechos son rígidos, inmutables $y$ eternos" (39). (Ver cita 22).

A.2). La Constitución responde a una de tipo escrito y rígido acorde con las exigencias de seguridad. Así todas las Constituciones, con matices de rigidez, establecen un procedimiento auto-defensivo, para sustraer de la vía ordinaria la modificación de la misma. Sin embargo, aparece como fundamental la construcción de un canál para que el derecho pueda ser transformado por el derecho mismo (40).

B) La existencia de un sistema de separación de poderes, que tiende fundamentalmente a asegurar la distinción entre las esferas de la creación de la ley (función legislativa), con la de aplicación de la misma (funciones ejecutivas $y$ judiciales).

Dentro de este planteamiento, "se reputa el poder legislativo como el poder supremo del estado, vinculándoselo con el ejercicio de la soberanía" (41).
C) No hay Estado de Derecho sin imperio de lá ley como expresión de la voluntad general. No se obedece la voluntad de los hombres, sino de la ley objetiva, formalmente creada por el órgano representativo de la voluntad del pueblo.

C.1). Existe una prelación de leyes. La Constitución conexiona y subordina a las demás leyes y les otorga una coherencia de significado. Por ello resulta de fundamental importancia dotar al Estado de un mecanismo de control de la constitucionalidad de las leyes.

C.2). Subordinación de la Administración. Esta deberá actuar siempre con sujeción a una ley preexistente. Se limita así al máximo los poderes discresionales y políticos de la administración, dotándola generalmente de un sistema de control jurisdiccional contra las posibles infracciones legales.

D) “La constitución sublima la vida civica $y$ política, erigiendo al ciudadano en una categoría fundamental de la dinámica estatal. De allí que los derechos políticos, el sufragio, los partidos políticos, absorban la atención del constitucionalismo clásico, y sean concebidos como imprescindibles para la libertad. La libertad política alcanza el nivel de la libertad civil" (42).

En apretada síntesis, son éstas las características del constitucionalismo clásico. Estos principios han estado presentes entre nosotros $y$, además de ser el contenido principal de los textos de derecho constitucional, han sido los temas centrales de preocupación en todas las constituyentes.

Cuando líneas atrás afirmábamos que en nuestro país había existido una actitud sacralizadora de la constitución, queríamos resaltar, precisamente, que eran los valores fundamentales del constitucionalismo clásico los que se habían elevado a la categoría

(39) Loc. cit.

(40) El artículo 236 de nuestra Constitución establece el procedimiento de reforma. Sobre los alcances de este procedimiento y sobre la posibilidad de modificar las bases mismas del régimen político ver: PAREJA PAZ SOLDAN, José... Derecho Constitucional Peruano. Lima, Ediciones Libreria Stidium, 1966; p. 559.

(41) BIDART CAMPOS, Germán. . op. cit. p. 39.

(42) Ibidem, p. 41. 
de valores fundamentales de todo ordenamiento juridico-constitucional. Así, una percepción valorativa abstracta e intemporal, se había impuesto sobre ta consideración y análisis de nuestra realidad socio-política.

Resta anota que el Constitucionalismo prevé la defensa del mismo. En realidad, cualquier sistema legal, dota al aparato del Estado de los mecanismos suficientes para asegurar su vigencia y continuidad. De esta naturaleza son las disposiciones legales que, en muchos casos, se encuentran incorporadas a la Constitución $y$ en otras -como en el Perú- a las leyes penales, que establecen como conducta punible la insurrección contra el ordenamiento legal vigente o los funcionarios. Muchas veces, este afán defensivo del sistema se ve plasmado en leyes particulares, promulgadas ante situaciones concretas que se conceptúan peligrosas para el orden constitucional (43).

\subsection{Vigencias y mutaciones constitucionales.}

El constitucionalismo trata de encerrar dentro cauces estrictos la vida del Estado. Este intento tropieza con dificultades de índole diversa que traban su vigencia real, entre ellas podemos anotar el persistente problema de la insurrección; sin embargo, no es el único.

Diversos autores se han ocupado del tema de la crisis del constitucionalismo, sobre todo en relación al constitucionalismo clásico, coincidiendo en que el problema constitucional más agudo, no está en la redacción de constituciones técnicamente perfectas y axiológicamente valiosas, sino en lograr la realización de determinadas pautas de valor en un orden real. mente vigente.

$Y$ aqui encontramos un problema particular. mente agudo en países como los nuestros, donde se han traspasado instituciones $y$ promulgado textos constitucionales totalmente al margen de su contexto social y económico, en virtud de una aceptación casi siempre a-priorística de postulados que en si mismos aparecían valiosos. Ello ocurrió con los principios del constitucionalismo clásico que han sido los inspiradores de nuestras constituciones republica. nas.

Ello hace, por otro lado, que la crisis del cons. titucionalismo a la cual la doctrina ha dedicado tan- tas páginas, sea mucha más aguda en países donde las fórmulas constitucionales nunca fueron respuesta a una exigencia de la realidad. El desajuste es pues mayor donde, como alguien ha dicho, se ha dado sólo un constitucionalismo postizo.

Bidart Campos sintetiza con precisión los perfiles de esta crisis. "Decir que el constitucionalismo clásico ha entrado en crisis, quiere decir que las creeencias básicas en que se sustentaba su funcionamiento están en curso de perder vigencia, o la han perdido ya. Significa que el mundo contemporáneo (...) está cambiando su repertorio de creeencias, de vigencias constitucionales; que la perspectiva es otra (...) Algunos problemas de los que el constitucionalismo clásico se hacía cargo ya no son problemas, o son desplazados por otros de importancia mayor $(\ldots)$ el sustrato ideológico del constitucio. nalismo clásico ha perdido su fuerza. En segundo término, ha entrado en crisis la idea positiva de legalidad (...) y con el positivismo ha sido cuestionado el racionalismo, hoy no impera la idea común en esa razón general, abstracta, invariable, que deducía a priori los derechos y las libertades, ni se rinde culto a la ley como formulación racionalista objetiva de un deber como formulación racionalista objetiva de un deber ser inmutable; ni se acepta la identificación del derecho con la ley, de los jurídico con lo legal, o to que es peor, la justicia con la ley (...) Todo giraba en torno a la legalidad, de la regulación normativa; la ley objetiva, impersonal, inviolable, agotaba la normatividad; y esa provisión normativa se suponía definitiva, suficiente $v$ estable para demarcar la vida constitucional, convirtiéndose en algo asi como una organización rígida: la constitución quedaba formalmente "dada", formalmente construida. Pues bien, todo este normativismo legal ha sufrido un impacto tremendo con las doctrinas vitales: la vuelta al mundo, la realidad, a la vida, a lo social, nos han hecho mirar un poco a las conductas, a los comportamientos y no solamente a las normas, no sólo al deber ser, sino al ser. Las fuerzas de la realidad, los vínculos de lo social, el acercamiento a la vida nos han descubierto que la ley carece de esa fuerza normativa que se le atribuía;

(43) Ver: Sección Décima del Código Penal que se ocupa de los "Delitos contra los Poderes del Estado y la Autoridad de la Constitución", tipificando el delito de rebelión armada y rebelión calificada. Asi como la ley 15590, con el objeto de reprimir las guerrillas, promulgada en agosto de 1965. 
que la costumbre, los usos, el derecho espontáneo, constituyen una fuerza contra la cual a veces se torna impotente la previsión normativa de la ley". (44).

Muchos de los problemas que pone de manifiesto la crisis del constitucionalismo clásico, tratan de superarse con la incorporación en los textos constitucionales de los postulados del llamado constitucionalismo social. Casi todas las constituciones de América Latina sufrieron el impacto de esta corriente a partir de la primera post-guerra. La Çonstitución mexicana había sido una versión anticipada de ello.

Esta corriente pone sobre el tapete una problemática diversa. No se trataba de seguir declarando derechos individuales intangibles que en definitiva nadie negaba, sino de incorporar al campo del derecho la búsqueda del bien común con precisas metas de indole económica, social y política.

En el Perú, las Constituciones de 1919 y 1933 acusan la influencia de estas corrientes. Sin embargo, subsiste el problema de la distancia entre la realidad que se pretende normar, y el texto constitucional formalmente vigente, elaborado dentro de las concepciones clásicas "puestas al dia" con las nuevas corrientes que se hacen eco del surgimiento de la llamada "cuestión social".

$Y$ es que la exaltación de las constituciones escritas ha llevado a identificar Constitución con Derecho Constitucional, habiéndose descuidado el estudio de lo que constituye la realidad constitucional. Se entendió que sólo habia Constitución, en los pueblos que tenían una plasmada en un texto de acuerdo a los moldes clásicos, dejando de lado la realidad de que todo pueblo tiene una estructuración constitucional.

Todo régimen político respira una atmósfera valorativa. Los valores tienen un ingreso histórico en cada época a cada comunidad, y la Constitución, plasma en normas tales valores para reglar la realidad, para tratar de organizar jurídicamente la convivencia social.

En este orden de cosas es que se produce el problema de las vigencias constitucionales sobre el cual queremos llamar la atención en este trabajo. Una Constitución y las leyes de un país pueden ser formalmente válidas y axiológicamente valiosas pero pueden tener, en el orden de la vigencia, una total incongruencia con la realidad.

Por ello, resulta fundamental determinar el ámbito del derecho constitucional.

"El derecho constitucional abarca, pues, lo que dicen los textos constitucionales y lo que se hace en la realidad existencial, Dice bien García Pelayo que el derecho constitucional vigente no es la pura norma, sino la síntesis de la tensión entre la norma y la realidad con la que se enfrenta. La forma de estado no es siempre la que describe la constitución; puede haberse transformado en los hechos. Piénsese no más en la constitución que pierde vigencia con el advenimiento de una revolución. . Similarmente, las relaciones de poder y sus contactos con los hombres no siempre acaecen como lo prevé la constitución escrita. Los grupos de presión, para citar una realidad contemporánea, no tienen cabida en el esquema de esa constitución, no obstante lo cual están allí, frente a ella, dentro de la constitución real, dando presencia a núcleos que van resquebrajando la estructura que se titula representativa". (45).

En esta línea, resulta de interés el punto de vista de Bidart quien expone la teoría de las mutaciones constitucionales $y$ la desconstitucionalización, pero todo ello enmarcado dentro de la tesis de la existencia de un derecho constitucional consuetudinario, lo cual hace que en el mundo de la realidad, de las vigencias constitucionales, pueda existir una constitución real, viviente, distinta a la escrita y hasta contrapuesta.

Sostiene Bidart que pocas leyes como la constitucional se prestan más al impacto de la realidad. De modo que es posible la existencia de conductas consuetudinarias contrarias a la constitución escrita, a las cuales "podremos fulminar de invalidez... pero no podremos despojarlas de realidad, de vigencia y de facticidad..." (46).

Como se aprecia no estamos ante un problema de validez o de valor, sino de facticidad, hay que

(44) BIDART CAR:POS, Germán... op. cit., p. 47 y sigs. 445) Ibidem, p. 16

(46) Ibidem, pp. 75-76 
definir si la costumbre entra en el campo constitucional o no. Bidart y Poviña (47) sostienen la constitucionalidad de la costumbre.

"Dentro del orden de la realidad, las conductas llegan en muchos casos a instaurar vigencias opuestas a la constitución escrita, llegan a normativizar extralegalmente otra constitución. Este fenomeno al que llamamos desconstitucionalización, nos obliga un poco a meditar en la fuerza de la costumbre..." (48).

Así, las mutaciones constitucionales aparecen como un fenómeno que se produce en los Estados que tienen una constitución escrita, las cuales sin someterse el procedimiento de reforma formal, ad quieren un sentido, un contenido nuevo y distinto en el orden de la realidad.

La primera mutación constitucional se da cuando se instaura una práctica que no se opone a la constitución pero que tampoco estaba prevista por ella. El ejemplo del partido político lo señala Bidart como tipo de esta mutación, la cual fue recogida posteriormente por muchas de las legislaciones escritas. También puede ser el caso de alguna atribución de urgencia. Es el caso de mutaciones por adición, pero también las hay por disminución. Estamos ante el segundo tipo, cuando ciertos ámbitos o partes de la Constitución escrita pierden vigencia.

El tercer caso de mutación se da por el uso de normas constitucionales con un sentido diverso al de la finalidad perseguida por la Constitución.

Finalmente, encontramos lo que Bidart denomina desconstitucionalización, incluído este fenómeno por la doctrina alemana en las mutaciones, implica ya una incongruencia total entre la constitución escrita y la práctica constitucional, la cual de hecho pone en vigencia un sistema constitucional distinto. Es el caso del paralelismo de dós constituciones - una escrita y otra real- del cual nos habla Poviña. Esta práctica distinta puede llevar hasta la vigencia de un sistema político distinto.

La forma como se da este proceso de desconstitucionalización la describe Bidart:

"En el proceso de desconstitucionalización tal cual hemos conocido a través de Alemania na- cional-socialista, de Italia fascista, de la Cuba de Castro y de la propia Argentina en el régimen de Perón, se ha transitado por las siguientes etapas: 1. La práctica política del Estado, puesta en acción por las personas que son titulares del poder, introduce una costumbre contraria a la constitución escrita vigente en ese momento. 2. Cambia la decisión politica suprema y la constitución escrita pierde vigencia. 3. La normatividad extralegal da origen a otra constitución. que es la vigente a partir de ese instante. 4. Es común que, para remediar el fenómeno de desconstitucionalización, y restablecer la identidad entre la constitución escrita y la vigente en la realidad, se proceda a reformar la constitución: la vigencia se incorpora como norma escrita a una nueva constitución normada legalmente...

son los órganos del Estado -en definitiva, los individuos investidos de esa calidad por la titularidad del poder- los que crean vigencias constitucionales contrarias a la constitución escrita" (49).

Aparece así la constitución real como el conjun. to de vigencias constitucionales, es decir como el funcionamiento efectivo de las instituciones politicas. "Esta constitución real es el conjunto de vigen. cias que, en oposición a la constitución escrita, se ha impuesto en un proceso de desconstitucionalización a impulso de quienes detentan el gobierno. Tal el fenómeno conocido con el nombre de poder normativo de la fáctico" (50).

Creemos que el estudio de las mutaciones constitucionales resulta de gran interés en paises que sufren los desajustes consecuentes de un constitucionalismo importado. En ese sentido en el Perú cabe señalar la antigua preocupación por la falta de vigencia de nuestras constituciones, frente a lo que venimos caracterizando como mutaciones constitucionales. Preocupación que la siguiente cita expresa.

(47) POVIÑA, Jorge Raúl. . Costumbres y usos constiturionales. Tucumán, Inst. de Derecho Público de la Univ. de Tucumán. 1950.

(48) BIDART CAMPOS, Germán. . op. cit. p. 72

(49) Ibidem, p. 144

(50) BIDART CAMPOS, Germán. . La estructura tridimensional del Estado. En: Revista de Estudios Politicos (Madrid), 1966, No. 149; p. 16. 
"El Estado en el Perú no es un Estado normado por la Constitución, sino un Estado arrastrado por los hechos, empiricamente, hacia una organización caprichosa que no es Democracia, de la que sólo tiene los vicios burocráticos y presupuestales del parlamentarismo, sin las virtudes esenciales de la libertad ciudadana y del control eficiente de los Poderes... Es una pseudo-democracia, es un pseudo-totalitarismo, es un Estado al que se le puede aplicar la definición de dolo de Servio Suplicio... se simula una cosa y se hace otra" (51).

Como hemos anotado ya, estos fenómenos de mutación constitucional pueden ocurrir en cualquier Estado con constitución escrita, pero ocurren con más frecuencia en aquellos donde la Constitución se encuentra más distante de la realidad social, sea porque sus principios fueron adoptados con abstracción de ella, o porque la Constitución se ha mantenido inmutable al margen de las transformaciones de la sociedad que pretende estructurar.

Excede a los alcances de este trabajo, pero sin duda const.tuye tema trascendente de investigación, lo que podríamos señalar como una constatación y explicaciór de las mutaciones constitucionales habidas en el Perú a partir de 1933. Una somera revisión de la Constitución vigente, nos muestra como una gran parte de ella tiene vigencias constitucionales totalmente distintas, en lo que se puede deno minar la constitución real.

Así, si tomamos los diversos Títulos del texto constitucional observamos que el fenómeno de las mutaciones se ha presentado en casi todos. La ideología jurídica predominante admite con tolerancia que las vigencias constitucionales puedan ser totalmente distintas en algunos Títulos (Título IV: Ciudadania y Sufragio; Título $V$ : Poder Legislativo; Título VII: Poder Ejecutivo; etc.l, o que incluso éstos sean verdaderamente puestos en suspenso, por ejemplo en épocas de gobierno de facto. Admite igualmente, sin mayor preocupación, que partes enteras de la Constitución no hayan llegado a teneı vigencia nunca (Senado Funcional, Consejos Departamentales). Sin embargo, la preocupación constitucionalista aflora con energía ante otras mutaciones, por ejemplo en el Título II, sobre Garantías Constitucionales, cuya inclusión en el texto constitucional responde al principal propósito del Constitucionalismo (supra 3.1.). En este Título se encuentran plasmados los valores fundamentales del Estado de Derecho.

Es por ello, que generalmente cuando encontramos la implantación de vigencias constitucionales distintas en el ámbito de disposiciones constitucionales que tienén que ver con los principios ordenadores del Estado, podemos estar ante un proceso de desconstitucionalización en el que se puede dar la vigencia real de principios y de pautas de valor ajenos al orden constitucional formalmente vigente, ca. si una nueva Constitución.

En cambio, las mutaciones constitucionales en otros ámbitos, suelen no afectar las raices mismas, y pronto no son otra cosa que variantes factuales del mismo sistema. Los golpes de Estado son un ejemplo de ello.

Por ello un estudio como el propuesto, creemos que debe llevar a detectar y a explicar las mutaciones constitucionales, su ámbito y significado. Creemos que este estudio debe ser abordado teniendo en cuenta dos etapas, una anterior a 1968 y otra posterior a ese año, diferenciadas porque a partir de entonces se asigna específicamente un rol supletorio a la Constitución. En ambas etapas se dan mutaciones constitucionales, el significado de ellas depende en gran medida del ámbito de las disposiciones en que se presenten. Como hipótesis podríamos establecer que es a partir de 1968 que las mutaciones constitucionales se trasladan del ámbito de las disposiciones organizativas del Estado, al ámbito de los principios mismos de la Constitución.

Algún aspecto de esta problemática tratamos de estudiar com mayor detenimiento en este artículo: lo relativo a los gobiernos de facto, que precisamente hemos querido plantear en este contexto, pero otros aspectos muy significativos, requieren de un trabajo distinto.

La alteración de las bases de una Constitución por vía de mutación constitucional, es decir mediante el mantenimiento de la vigencia formal del texto, pero con la introducción de vigencias distintas, nos

(51) TOLA, Fernando.. Conforchia dictada el 8 de setiembre de 1943 en la Lniversidad de San Marcos. En: Hay Democracia en cl Perü?: $p$. 6. 
enfrenta con el rol mismo de la Constitución en el ordenamiento jurídico. Pareciera que la Constitución no siempre otorga a todo el sistema, esa íntima coherencia de significado, y que por la práctica, por leyes de menor jerarquía, o por la recreación del derecho que implica su interpretación, es posible introducir valores, o plasmar un ordenamiento jurí. dico realmente distinto al que prevé la Constitución.

En este sentido el reclamo del Colegio de Abo. gados de Lima (cita 22) ante el Proyecto de Ley de Propiedad Social, es significativo. $Y$ es gue no cabe duda que, en materia de propiedad por ejemplo, las recientes disposiciones legales en ese ámbito, así como la práctica y la interpretación de los funciona. rios encargados de la aplicación de algunas leves, ha conducido a configurar en el ordenamiento, sistemas de propiedad que en puridad no concuerdan con el que el constituyente de 1933 plasmó en la Constitución.

Por todo ello resulta de interés un trabajo que no sólo constate las mutaciones constitucionales habidas hasta hoy (casi podría escribirse una Constitu. ción paralela a la formalmente vigente), sino que analizándolas pueda ser un aporte al conocimiento de una ley fundamental construida sobre nuestra realidad.

\section{El Problema de los Gobiernos de Facto.}

\subsection{Revolución, Golpe de Estado y Funcio- narios de Facto.}

El distinto título originario diferencia al gobier no de jure del gobierno de facto. Aquel ha llegado al poder por derecho, de acuerdo al procedimiento establecido por la Constitución. El gobierno de fac to accedio al poder al margen det cauce legalmente señalado, en una forma no prevista por el ordenamiento jurídico vigente.

Aunque las perspectivas para analizar el problema de los gobiernos de facto han sido diversas, nos interesa precisar conceptos y resaltar el interés del fenómeno, atendiendo fundamentalmente al impacto que producen estos gobiernos en el ordenamiento jurídico.

Una precisión necesaria desde esta perspectiva, es la tendiente a diferenciar la revolución del golpe de Estado, términos que muchas veces son usados indistintamente para describir el mismo fenómeno. (52).

Creemos que la diferencia fundamental estriba en el impacto en el ordenamiento jurídico. La revo. lución es "el quebranto de un ordenamiento jurídico y la instauración de otro nuevo, efecutados en forma ilegal, es decir, con un procedimiento no previsto por el ordenamiento precedente" (53), de mo. do que la legalidad futura se asienta sobre bases distintas a la que existía con anterioridad a la revolución. El golpe de Estado, a nuestro entender, tiehe un alcance más restringido. Significa casi siempre una simple sustitución de funcionarios - generalmente violenta- en una forma no prevista por el ordenamiento jurídico.

$\mathrm{Si}$ entendemos ordenamiento jurídico como "un sistema cerrado de normas, determinado por una intima coherencia de significado" (54), vemos que esta sustitución puede darse, en primera instancia, a nivel de la Constitución escrita, concebida precisamente como la Ley Fundamental que da esa coherencia de significado. Se habrá dado una revolución. cuando la norma base de un ordenamiento ha sido cambiada por otra.

Pero, ¿es posible que el ordenamiento jurídico sea cambiado sin la sustitución de la ley fundamental? ¿Esta coherencia está dada siempre y en todos los casos por la Constitución?

(52) Ver: CHIRINOS SOTO, Enrique... Teoria y Concepto del Golpe de Estado a la Luz del Derecho Constitucional. en: 2 Análisis, Lima, Ed. Minerva, 1974.

Por otro lado, CATTANEO, en el trabajo que hemos citado (p. 91 y sig.) los identifica, pero en base a que "ningún ordenamiento juridico admite una violación, aunque sea parcial, de su propia legalidad. . una modificación, aunque sea solamente de las normas constitucionales, produce, como se dijo, el cambio de todo el ordenamiento turidico...".".

(53) CATTANEO, Mario. . op. cit., p. 61

(54) ROSS... On Law and justice, London, 1958. Citado por Cattaneo, Mario... op. cit., p. 76. 
Linares Quintana sostiene que "la revulución comporta el cambio fundamental en las ideas e instituciones del Estado" (55), coincidiendo así con Burdeau, para quien lo que define una revolución es la sustitución de una idea de derecho por otra. La revolución aparece asi como un hecho jurídico, que importa el cambio de las ideas o instituciones del Estado; un cambio en la ideología politica, cristalizando en fórmulas jurídicas.

Tanto en la revolución como en el golpe de Estado se da la ruptura de la continuidad prevista y garantizada por la Constitución. Ahora, de acuerdo a lo que, hemos venido precisando, la revolución puede darse a partir de un suceso sủbito que sustituya la norma fundamental, o también por mutación constitucional, mediante la instauración de vigencias distintas. Como bien puntualiza Bidart, "la revolución involucrará un cambio institucional que puede llegar a cambiar la Constitución, si no siempre en el texto por reforma formal, muchas veces en la práctica por mutación material; el golpe de estado sólo reemplaza a las personas de los gobernantes"' (56).

Por tanto, la suplantación del ordenamiento que caracteriza a la revolución, se puede dar tanto como un hecho violento o a través de la instauración de un conjunto de costumbres o usos que cambian totalmente la decisión política del Estado expresadas en mutaciones constitucionales, creando un dualismo de constitución escrita y practicada.

En ese sentido, podemos afirmar que en el Perú a partir de. 1968, no sólo se ha dado la suplantación de la norma base, en virtud del art. 5o. del Estatuto Revolucionario, sino se ha iniciado un proceso de desconstitucionalización, que aún no se ha estudiado, y que va implantando a nivel de las vigencias constitucionales, principios $\vee$ prácticas distintas a las de la Constitución.

En relación con ésta, es interesante resaltar el caso cubano a partir de la revolución. Formalmente la Constitución de 1940 se mantiene en vigor, recién en estos días se trabaja en Cuba en una nueva Constitución, sin embargo a través de dos vías se ha dado una suplantación del orden constitucional. Por un lado mediante la promulgación de leyes con rango constitucional (una Ley Fundamental $y$ las leyes de Reforma Agraria, Educación y Reforma Urbana, por ejemplol, por otro, mediante la instauración

108 práctica de vigencias en base a una decisión política, distintas totalmente a las previsiones constitucionales.

\subsection{Efectos legales de los Gobiernos de Facto.}

En definitiva son los efectos legales en el orde. namiento jurídico, producidos por el hecho no previsto, lo que configura una revolución o un golpe de Estado.

Previo al análisis de los diversos niveles en los cuales se pueden dar estos efectos, hace falta una breve referencia histórica. De acuerdo a lo que hemos precisado en el acápite anterior, en el presente siglo, constituyeron golpes de Estado en el Perú el derrocamiento de Billinghurst por Benavides en 1914, el derrocamiento de Pardo en 1919, el derrocamiento de Bustamante por Odría en 1948 y el derrocamiento de Prado en 1962. Asimismo, constituye un golpe de Estado el de 1936, cuando el Congreso anula las elecciones $y$ porroga el mandato al General Oscar R. Benavides. Aunque con mayores efectos en el ordenamiento -que concluyen en la convocatoria a una Constituyente y la dación de la Constitución de 1933- el derrocamiento de Leguía por Sánchez Cerro, puede inscribirse también en esta caracterización.

En 1968 la situación es distinta. La insurrección armada no se dirige sólo al cambio de funcionarios sino también a la modificación de un sistema. Ello es claro en el Manifiesto revolucionario, en el Estatuto $y$ en las posteriores manifestaciones del gobierno. La Constitución está supeditada jerárquicamente a los objetivos del gobierno revolucionario $y$ a su Estatuto (57).

Por otro lado, no sólo se objetan a los funcio-

(55) LINARES QUINTANA, Segundo... op. cit., T. VI, p. 350.

(56) BIDART CAMPOS, Germán. . Derecho Político, Buenos Aires, Ed. Aguilar, 1962; p. 563.

(57) Situación similar a la producida en Argentina en 1966. Ver: Estatuto de la Revolución Argentina y Proclama de las FF.AA., en: BIDART Campos, Germán... Derecho Contitucional, Tomo 11 . 
narios en el poder, sino a un sistema económico, politico y social, cuya sustitución se persigue a través de una revolución, que por tanto, alcanza también el aspecto jurídico. Esta intención la encontramos claramente manifestada en diversas ocasiones.

"La Revolución iniciada no significa únicamente la toma del poder por sus gestores, sino que traduce esencialmente las aspiraciones de millones de peruanos que han sufrido la frustración de sus más caras esperanzas... Por eso como intérpretes de ese anhelo, iniciamos la Revolución con un hecho y una base doctrinaria concretada en el Estatuto del Gobierno Revolucionario que, junto con la Constitución, hoy orienta y guía su desenvolvimiento, evitando interpretaciones equivocadas con el fin de que la doctrina de la Revolución no sea jamás distorsionada" (58).

"Una caduca estructura política, que de muy poco o nada sirvió a millones de peruanos, fue utilizada para dar visos de legalidad a la injusticia social; se tráficó con los más nobles ideales de libertad y democracia, constitucionalismo y patriotismo. Contra todo esto hemos insurgido resueltamente decididos a iniciar el proceso de desarrollo a fin de lograr la emancipación económica del Perú (59).

"Finalmente, una nueva Constitución es indispensable como instrumento jurídico fundamental del Estado... que fielmente refleje los cambios sustanciales que están ocurriendo y que van a ocurrir en nuestra sociedad

... Sin ella, la Revolución Nacional quedaría trunca, y nuestro pueblo carecería del maś importante instrumento jurídico para garantizar la permanencia y la continuidad de la obra transformadora que hemos iniciado". (60)

\footnotetext{
"Algurios esperaron cosas muy distintas y confiarón en que, a la vieja usanza, ascenderíamos al poder sólo para convocar elecciones y devolverles todos sus privilegios. Quienes así pensaron, estuvieron y están equivocados. A esta revolución no se le puede pedir que respete las normas institucionales del sistema contra el cual insurgió. Esta revolución tiene que crear, está creando ya, su nuevo ordenamiento institucio-
}

nal.

.. La realidad de una revolución así, sólo podía concretarse rompiendo ese ordenamiento tradicional. La legitimidad de este Gobierno Revolucionario no puede, pues, estribar en el respeto por las reglas de un juego político decadente que sólo benefició a los grupos privilegiados del país...

Por eso nuestra legitimidad no viene de los votos de un sistema político viciado de raíz porque nunca sirvió para defender los intereses del pueblo peruano. Nuestra legitimidad tiene origen en el hecho incontrovertible de que estamos haciendo la transformación de este país... Esta es la única legitimidad de una revolución auténtica como la nuestra". (61)

"... Por tanto no somos los actores de un golpe militar. Somos los gestores de una Revolución". (62)

Las citas que anteceden corroboran 10 dicho. El sustento del Gobierno de la Fuerza Armada no está en la legalidad del orden jurídico contra el cual insurgieron. El nuevo orden está basado en el Estatuto (en el cual se han formulado los objetivos generales de la Revolución) promulgado precisamente para hacerla posible. La consolidación del nuevo orden de cosas - según se ha anunciado reiteradamente- se dará con la promulgación de una nueva Constitución.

Es interesante destacar como el Estatuto abre un período de creación jurídica, de verdadero tras. tocamiento del ordenamiento que existía hasta entonces. No se sustituye integramente la Constitución (ello vendrá después), se le asigna un rol supletorio. Entretanto, por la vía legislativa (Decretos-Leyes y disposiciones de menor rangol, se inicia un periodo

(58) VELASCO, Juan. . Discurso en el Centro de Instrucción Militar, 31/1/1969. En: VELASCO, la voz de la Revolución; pp. 19-20.

(59) VELASCO, Juan... Discurso en la inauguración del $X I I$ periodo de sesiones de la CEPAL, 14/4/1969, En: Ibidem; p.36.

(60)

(60) Ibidem, pp. 87-88.

(61) VELASCO, Juan. . Mensaje a la Nación en el Primer Aniversario de la Revolución. 3/10/1969. En: Ibídem, p. 94.

(62) VELASCO, Juan. . Discurso en la ciudad de Piura. 8/10/69. En: Ibidem; p. 116-117. 
de importantes cambios en el ordenamiento jurídico del país. La práctica administrativa contribuye también a ello. Tenemos, pues, que el Estado encuentra en las disposiciones de rango inferior un instrumento más adecuado para plasmar sus decisiones. No sólo la Constitución tiene un rol supletorio, el Derecho Constitucional en el Perú, se modifica por vigencias constitucionales distintas y por disposiciones de rango inferior.

Resta señalar que la distinción entre golpe de Estado $y$ Revolución tiene que ver con el fenómeno de las mutaciones constitucionales. En el Perú, los golpes de Estado han pertenecido a la constitución real, $y$ han sido verdaderamente mecanismos utilizados a ese nivel para accdeder al gobierno. No son simple factualidad, son vigencias constitucionales.

En las épocas de vacío de poder o de crisis política, en la práctica constitucional, por mutación, se ha asignado a la Fuerza Armada un rol distinto al señalado por la Constitución, de modo que se puede afirmar que los golpes de Estado han formado parte de la constitución real, en la cual son perfectamente previsibles las circunstancias en las cuales la sustitución de gobiernos podía darse, ciertamente en una forma no prevista por el ordenamiento. El fenómeno revolucionario, en cambio, tal como lo hemos conceptuado, excede a este marco.

La mutación constitucional a la que nos referimos, no sólo alude a los golpes de estado, to hace al rol de la Fuerza Armada, que si bien está reglado por la Constitución escrita, ciertamente su intervención en la vida del Estado en la realidad constitu. cional, se ha ajustado más a la propia determinación de sus límites, que a los que le ha fijado la Ley Fundamental. Ello no solamente en cuanto a la decisión de cambiar gobiernos por la imposición de la fuerza, sino, durante los gobiernos de jure, en la definición de un rol que podemos señalar como político y que ciertamente está alejado del texto y del espíritu de la Constitución.

El carácter de mutación constitucional, lo vemos claramente en el tratamiento que se hace en algunos casos del problema, que denota, efectiva mente, la aceptación del rol asumido por la Fuerzá Armada.

"Sin que figure en el texto escrito de nuestras Constituciones, las Fuerzas Armadas tienen una situación de control y de predominio, siendo el único contrapeso a los extremismos y radicalismos, No exageramos esa intervención, a veces necesaria, sumiéndolas en la participación activista y apasionada de nuestras contiendas políticas por la concesión del sufragio a los militares, policía y marinos en servicio".

"Hay que deplorar la iniciativa y la intervención excesivas que la Fuerza Armada se ha atribuido, en la vida política. Pero a su vez, las clases dirigentes y los propios partidos políticos se han empeñado en provocar esas intervenciones, cuando se hallan en la oposición y surge algunas crisis política devorados por el rencor o la impaciencia. En algunos sectores castrenses se piensa equivocadamente que ellos tienen el monopolio del patriotismo y que son un poder fiscalizador encargado de supervigilar el gobierno y el Parlamento". (63).

La mutación constitucional que confiere a la Fuerza Armada funciones diversas a las reconocidas en el texto constitucional, ha sido bastante estudiada en el Perú $y$ en América Latina por historiadores y científicos sociales bajo el fenómeno del militarismo.

Pero, ligada con esta mutación constitucional, existe la otra, que hace del golpe de Estado un mecanismo para la sustitución de gobiernos, paralelo al mecanismo legal previsto constitucionalmente, EI golpe de Estado, a pesar de su manifiesta ilegalidad, constituye una forma de sustitución de gobiernos por acción de elementos militares en situaciones de vacío de poder o de crisis política, que es aceptada y funciona en la constitución real sin poner en peligro el sistema jurídico todo, ya que sólo se dirige al cambio de los funcionarios de gobierno.

\subsubsection{El Ejercicio del Poder constituyente.}

Analizando los efectos legales de los gobiernos de facto aspecto fundamental a ser considerado, es el del ejercicio del poder constituyente.

Resulta evidente la distinción de dos situaciones en la vida del Estado, una originaria, fundacional,

(63) PAREJA PAZ SOLDAN, José... op. cit. pp. 408 V 412. 
primigenia, en la cual se crea el Estado y se adopta una organización política y jurídica. Otra permanente, cuando el Estado se encuentra constituido; es la etapa de continuidad en la que el Estado organiza y desarrolla sus funciones sobre las bases establecidas en la anterior.

Este poder, que en el marco de las constituciones escritas y rígidas provee al Estado en ese acto primigenio, de una organización $y$ de su identidad política, es el llamado poder constituyente originario. Cattaneo lo ubica en un hecho de carácter político que da origen al ordenamiento jurídico. Señala que se denomina como "poder constituyente" a "la fuente suprema de producción de normas constitucionales $y$, por lo tanto, de todo el ordenamiento jurídico" y que "ese poder político, de hecho, que está en el orígen del derecho, es pre-jurídico, no disciplinable por el derecho". (64).

Én la etapa de continuidad, en la del poder constituido en base a ese acto fundacional, se acepta la existencia de un poder constituyente derivado - continuo, $y$ es el ejecido de acuerdo al procedimiento que el mismo ordenamiento constituciona! vigente ha previsto para modificar una Constitución.

El poder constituyente originario ha sido estudiado generalmente en vinculación con las concepciones predominantes del constitucionalismo clásico. Así Bielsa lo define como "La potestad que el pueblo tiene de darse un gobierno $y$ establecer las normas de convivencia social y jurídica que aseguren la libertad, mediante disposiciones protectoras de los derechos y deberes. Esas normas tienen su concresión positiva en la Constitución..." (65).

En este sentido es interesante resaltar la opinión de Bidart Campos, quien subraya la existencia de poder constituyente en toda organización estatal, tenga o no constitución escrita y rígida y los principios que esta recoja se ajusten o no a los principios del constitucionalismo clásico.

Aparece así el poder constituyente como "una facultad de acción que deriva del derecho originario de la colectividad, a proveer a su organización política y jurídica, imponiendo una Constitución" (66). El efecto, va a ser asentar al Estado como individualidad jurídica y política. Este poder es referido por algunos autores al derecho natural, otros lo fundan en el hecho político, en ambos casos es prejurídico, $y$ conviene distinguirlo del poder constituido que sí es jurídico.

La distinción que hemos efectuado entre poder constituyente originario $y$. derivado, nos es útil para distinguir dos formas de producción del derecho. Los mecanismos de producción de derecho y los canales establecidos para reformar la Constitución, se sitúan dentro del poder constituido $y$ en ejercicio del poder constituyente derivado. Al haber aceptado que la revolución implica la sustitución de un ordenamiento jurídico por otro, el tema del poder constituyente aparece en relación a la instauración del nuevo ordenamiento.

Para el constitucionalista Carlos Sánchez Viamonte, la consecuencia fundamental de toda revolución sería la de retrotraer el poder constituyente a una etapa de primigeneidad. EI "cerco constitucional" sería roto por la voluntad política de configurar un nuevo ordenamiento.

"Puede ocurrir que una revolución - no un simple golpe de estado- retrotraiga el poder constituyente al punto inicial, es decir, a la etapa de primigieneidad. Para eso es indispensable que la revolución asuma el significado de un acto de voluntad política inequívocamente dirigido a destruir el sistema de gobierno o estructura estatal o el orden jurídico, y se propongan declaradamente reemplazarlos por otros nuevos.

De lo contrario si se trata únicamente de un golpe de estado, para reemplazar los gobernantes y con ella la orientación política positiva, se permanece en la etapa de la continuidad, y con mayor motivo cuando el golpe de estado acata el orden jurídico establecido" (67).

Cuando se produce una insurrección y es derivado el ordenamiento jurídico, en una forma ilegal para ser sustituido por otro, estamos no sólo ante

(64) CATTANEO, Mario... op. cit.; p. 95.

(65) BIELSA, Rafael... Derecho Constitucional, Buenos Aires, Ed. Depalma, 1959 ; p. 89.

(66) BIDART CAMPOS, Germán ... Derecho Constitucional, p. 158.

(67) SANCHEZ VIAMONTE, Carlos... El Constitucionalismo, sus problemas. Buenos Aires, Editorial Bibliográfica Ar. gentina, $1957 ;$ p. 533. 
una revolución, sino ante el ejercicio fáctico del poder constituyente. Como señala Raúl Ferrero, "cuan. do se funda una comunidad estatal, o cuando se altera sustancialmente el régimen anterior, se da la situación constituyente, la cual se caracteriza por desconocer el derecho vigente $v$ fundar un nuevo sistema juridico" (68).

Estamos pues ante la fuerza normativa de los hechos. En este procedimiento ilegal de modificación el nuevo derecho encontrará su fundamento. Desde ese momento es eficaz. Rige un nuevo ordenamiento, el cual es obligatorio y es más, designará como ilícitas las infracciones a él.

\begin{abstract}
"A primera vista - dice Recasens Siches-resulta paradógico que un acto violento anti-jurídico pueda ser origen del Derecho; y sin embargo no hay duda de que así lo es. Si la condición para la existencia de un Derecho fuera la legitimidad de su aparición, nos veríamos obligados a reconocer que hoy, en toda la capa terrestre, no existe orden jurídico alguno, pues no hay pueblo cuya historia no cuente con una revolución consolidada" (69)
\end{abstract}

Sin embargo; cabe precisar que al asumir el poder constituyente, es decir la facultad de dar un nuevo orden, el periodo en que ésto se de puede tener una duración muy distinta. La sustitución del ordenamiento puede darse -según las coyunturas históricas- a través de un solo hecho, o se puede ingresar a partir del hecho violento en una etapa o período constituyente, en la cual a la negación del ordenamiento anterior suceda la paulatina instauración de un nuevo ordenamiento constitucional, que suele concluir en la isntauración de una nueva Cons. titución.

Es interesante resaltar como en 1966, cuando las Fuerzas Armadas argentinas asumen el poder de ese país, en la que se autodenomina Revolución Argentina, se promulgó un Estatuto "a efectos de cumplir con los objetivos de la revolución y en el ejercicio del poder constituyente" (70). Se invocó expresamente la facultad constituyente en cuya virtud, se establecís un nuevo ordenamiento que llevó a tomar medidas tales como la remosión de los magistrados judiciales, en vista de que los que hasta ese momento desempeñaban su cargo, respondían $y$ habian jurado el ordenamiento anterior (71).

Si bien en el Perú, cuando accede al poder el Gobierno de la Fuerza Armada en 1968, no se da una expresa invocación de la asunción del poder constituyente, como en el caso que indicamos, es evidente que la situación señalada por Sánchez Viamonte se presenta desde entonces. No sólo por la preeminencia del Estatuto sobre la Constitución, establecida por el mismo Estatuto, sino, porque desde entonces resulta evidente que a través de la voluntad política del gobierno, expresada legislativamente. se ha iniciado la destrucción del orden constitucional precedente, para la instauración de uno nuevo. Ello se ha venido dando a través de la promulgación de diversas leyes; algunas por su naturaleza son de indole constitucional, también por la promulgación de dispositivos que han venido afectando no sólo derechos, sino instituciones cuya defensa y configu. ración se daban en la Constitución de 1933 y, finalmente en la instauración de prácticas administrativas, que sin duda están produciendo verdaderas mu. taciones constitucionales.

En definitiva, podemos señalar que en cuanto efectos legales, una de las caracteristicas de la revolución en materia jurídica, es el ejercicio factual del poder constituyente, dirigido a llevar a cabo la vo. luntad inequívoca de sustituir al ordenamiento juridico vigente por otro nuevo.

\subsubsection{Constitución y Estatutos de los Gobiernos de Facto.}

Generalmente después de la ruptura de la continuidad constitucional no se dicta una nueva Consti-

(68) FERRERO, Raúl. . op cit pp. 151-152.

(69) RECASENS SICHES, Luis. Direcciones contemporáneas del pensamiento juridico, citado por DIAZ DOIN, Guilier mo. . Gobierno Revolucionario $y$ Gobierno de Facto. En Rev. de Jurisprudencia Argentina, 1963 - 11, p. 8.

(70) Estatuto de la Revolución Argentina.

(71) El art. 3o. del Estatuto dice: "el Gobiemo ajustará su cometido a las disposiciones del Estatuto, a las de la Constiunción Nacional y leyes y decretos dictados en su conseuencia en cuanto no se opongan a los fines anunciados en cl acta de la Revolución Argentina". 
tución. Bidart señala que lo más frecuente "es que en primer momento la revolución se sostenga con una constitución normativizada espontáneamente, o sea que normativice, una normalidad surgida rápidamente por el impulso del propio hecho revolucionario triunfante". (72).

Pero to que ha sucedido generalmente en el $\mathrm{Pe}$. rú es que, después del triunfo de la insurrección, inmediatamente los nuevos gobernantes adoptan una posición ante la Constitución vigente, la que se manifiesta a través de un Estatuto.

Tales Estatutos pueden significar simplemente el establecimiento de un "puente" entre los funcionarios de facto $\mathrm{y}$ las funciones previstas por la Consti. tución. Lo único que persiguen es atribuir a los funcionarios de facto las funciones de gobierno que dentro de la normalidad constitucional corresponden a los funcionarios legales. Su función es pues de adecuación. Ası, por ejemplo, es frecuente la atribución de las facultades legislativas al Ejecutivo. Por otro lado, dichos Estatutos pueden implicar en cambio, una nueva norma fundamental. Es decir, la sustitución del ordenamiento jurídico vigente hasta entonces. Esto sucede, cuando por virtud del hecho revolucionario, los gobernantes de facto erigen al Estatuto en nueva norma base, trastocando la pirámide jurídica de un país.

El carácter del Estatuto va à corresponder a dos tipos distintos de gobiernos de facto, según se trate de un golpe de. Estado o de una revolución.

En el Perú, los gobiernos que accedieron al poder en 1930, 1948 y 1962 promulgaron sus respectivos Estatutos, los cuales, en todos los casos, cumplieron el objetivo de acondicionar a los funcionarios de facto a las funciones establecidas por la Constitución. Son Estatutos que no pretendieron la instauración de un nuevo ordenamiento; correspondieron a golpes de Estado y pretendieron únicamente dar una cierta adecuación legal al ejercicio fáctico del poder. Si bien acataron la preeminencia de la Constitución, la pusieron en suspenso en partes significativas (73).

El Estatuto de 1930 se limitó a establecer una relación entre los cargos impuestos de facto por la Junta y los vigentes en la Constitución de 1920. Igualmente los Estatutos de 1948 y 1962, (entre los que no hay diferencias) entre sus considerandos señalan:

"Que es indispensable dictar un Estatuto que determine las atribuciones y regule el funcionamiento de la Junta Militar de Gobierno, dentro de las facultades que la Constitución acuerda a los Poderes Legislativo y Ejecutivo" (Estatuto de 1948 , reproducido casi textualmente en 1962) (74)

El Estatuto de 1968 es sustancialmente distinto. No es una norma que pretenda exclusivamente ajustar el ejercicio del poder $y$ de algunas funciones públicas al esquema de la Constitución; fue promulgado para servir de base a un nuevo sistema legal, en ese sentido constituye un Estatuto revolucionario. Asimismo, dicho Estatuto sienta la base inicial de un nuevo sistema de gobierno, distinto al previsto por la Constitución y que aparece con una manifiesta voluntad de continuidad, un sistema de gobierno asentado en la institucionalidad de la Fuerza Armada, cuya base es el Estatuto, complementado en la práctica de los años de gobierno.

La vocación de continuidad que señalábamos líneas atrás y la voluntad de iniciar un proceso, hace que la intervención de la Fuerza Armada abandone su matiz circunstancial, planteándose la tarea de gobierno como un verdadero deber institucional, al cual el Estatuto le brinda un esquema y una organicidad.

(72) BIDART CAMPOS, Germán... . Derecho Constitucional, T.1., p. 633 .

(73) Baste tener en cuenta la Ley de Seguridad Interior promulgada en 1949 por la Junta de Gobierno, de la cual hizo uso no sólo la Junta instaurada en 1948, sine el go bierno de 1950 . Ella fue claramente anti-constitucional.

*Decreto Ley No. 110:19, o Ley de Seguridad Interior de la República.

Art. 310.- Por los fines que persigue este Decreto Ley y por la conveniencia de prevenir la consumación de los delitos de que trata, queda facultado el Ministro de Gobirno y Policia para adoptar las disposiciones preventivas que crea necesarias a fin de garantizar la tranquilidad politica y social y la organización y la paz interna de la República; no pudiendo intervenir la autoridad judicial correspondiente sino cuando los delincuentes hayan sido puestos en su disposición.

(74) En: GARCIA BELAUNDE, Domingo... op. cit., pp. 4.1.3.a. y sig. 
"Porque al Perú siempre le faltó una gran institución nacional que solidariamente cumpliera la impostergable necesidad de transformar sus viejas estructuras y solidariamente también, emprendiese con determinación la difícil tarea de llevarla a cabo. Este gran vacio que acusó nuestra historia, ha sido llenado a partir del 3 de octubre de 1968 , por la presencia institucional de la Fuerza Armada del Perú frente al Gobierno..." (74-A).

Los artículos 2o. Lobjetivos del Gobierno Revolucionario de la Fuerza Armada) y 5o. (la compatibilidad de la Constitución y las leyes con los objetivos del Gobierno, condicionan su vigencia) del Estatuto establecen las bases del nuevo ordenamiento. En virtud de esta norma, impuesta por un hecho de fuerza, al margen de la previsibilidad del ordenamiento vigente, la Constitución tiene un rol secundario, y rige en tanto no se oponga al Estatuto y a los objetivos del Gobierno Revolucionario. La prelación de leyes se ha alterado. El Estatuto no pretende "ajustar" funciones, fue promulgado como norma fundamental y se convierte de hecho, en la ley básica.

Dicha norma da fuerza de ley a los principios que han de guiar la acción del Gobierno, pero además diseña un sistema de gobierno diferente, basado en el aparato institucional de la Fuerza Armada que va a vertebrar la nueva organización gubernamental.

Fueron los Comandantes Generales del Ejército, Marina y Fuerza Aérea quienes ejercieron de hecho el poder constituyente $y$ dieron la norma básica del nuevo ordenamiento, dentro del cual se constituyen en la Junta Revolucionario (75); que de esta manera aparece como el organismo de mayor rango del nuevo sistema. Es el organismo que vertebra la naturaleza militar del régimen, vinculando las funciones de gobierno y su estructura con el aparato institucional de la Fuerza Armada. Ella no sólo genera la norma básica sino que va a mantener una función de control del cumplimiento del Estatuto y de los objetivos de gobierno. Asimismo. el título de los funcionarios de mayor rango emanará de la Junta. El Estatuto va a precisar la relación entre la Junta Revolucio. naria y la estructura de gobierno.

Va a corresponder a la Junta Revolucionaria de- signar al Presidente de la República e intervenir en la designación de los Ministros. Estos deben ser nombrados por el Presidente, pero con el acuerdo de la Junta, excepción hecha de los Ministros de Guerra, Marina y Aeronáutica (Art. 4to.), que necesariamente deberán ser los Comandantes Generales de las armas correspondientes (Art. 3ro.). Asimismo, uno de los miembros de la Junta presidirá el Consejo de Ministros: el Comandante General del Ejército y por tanto Ministro de. Guerra. La Junta Revolucionaria, por otro lado, participa también en la función legislativa con el Presidente y el Consejo de Ministros (Art. 6o.).

De esta manera se.establecen las atribuciones de la Junta Revolucionaria. Cabe destacar que en la función vertebradora que señalábamos, el Estatuto define funciones que sólo podrán ser desempeñadas por funcionarios en virtud de su situación militar, definida de acuerdo a las normas institucionales de la FF.AA. (76) (77).

(74-A) Velasco, Juan. . Discurso en la Asoc. de Ofi. ciales en retiro, 3/4/70. En: VELASCO...p, 19

(75) Estatuto del Gobierno Revolucionario.

Art. 3o.- "La Fuerza Armad́a del Perú, identificada con las aspiraciones del pueblo peruano, y representada por los Comandantes Generales del Ejército, Marina y Fuerza Aérea, constituidos en Junta Revolucionaria, asume el compromiso de cumplir y hacer cumplir decididamente el Estatuto y el Plan del Gobierno Revolucionarió.

Para este efecto los Comandantes Generales de los tres Institutos de la Fuerza Armada serán al mismo tiempo Ministros de Estado en los Despachos de Guerra, Marina y Aeronáutica respectivamente".

Art. 110.- "El presente Estatuto no sufrirá modificaciones y será refrendado por los Comandantes Generales del Ejército, Marina y Fuerza Aérea al constituirse en Junta Revolucionaria".

(76) Estatuto Revolucionario.

Art. 90.- "Los Comandantes Generales de los institutos armados continuarán rigiéndose, en lo que respecta a su situación militar, por las disposiciones legales vigentes. Al pasar a la situación de retiro, la designación del sucesor recaerá en el Oficial General de mayor antigüedad en el respectivo instituto".

(77) Cabe anotar un hecho de interés para el estudio del rol de la Junta Revolucionaria en la realidad. En marzo de 1973, sucedi6 un hecho imprevisto por el Estatuto Revoluionario: el Presidente quedó temporalmente inhabilitado para ejercer las funciones debido a una grave enfermedad. La Junta Revolucionaria, investida de poder constituyente, anunció mediante Comunicado que, por unanimidad, había 
El esquema de gobierno que delinea el Estatuto se precisará posteriormente, ya sea a través de la vía legislativa, o por la vía de la práctica administrativa. Así, por ejemplo, mediante los Decretos Leyes No. 17271 y 17532 se concretan las funciones del Primer Ministro, mientras que, en otros casos, sin que medie instrumento legal alguno, se han desarrollado sistemas que completan el esquema del Estatuto. Tal es el caso del mecanismo de consulta y generación de los dispositivos legales. EI COAP (Comité de Asesoramiento de la Presidencia de la República), dentro del mecanismo anotado, si bien está previsto en el Decreto Ley No. 17532, es el caso de una definición en la práctica de importantes funciones de gobierno.

"El COAP... es un organismo que ha creado este Gobierno y que es el asesor directo del Presidente de la República en todos los asuntos que competen al Gobierno. El COAP cumple además una función de gran coordinador entre todos los sectores de la administración pública. El COAP es la antesala también de todos los instrumentos legales a nivel de Decretos Leyes, Decretos y Resoluciones Supremas con la aprobación del Consejo de. Ministros. Esa es la función específica del COAP".

“...está dirigido por un Oficial General de la Fuerza Armada ... quien tiene a sus órdenes doce colaboradores, uno de ellos en situación de General de Brigada del Ejército...y once coroneles de las tres Fuerzas Armadas y las Fuerzas de Policía, o sea que en el Comité de Asesoramiento de la Presidencia ... están representados todas las instituciones militares que tienen responsabilidad en diferentes grados en el Gobierno..." (78)

\subsubsection{Los Decretos Leyes}

El ordenamiento jurídico en el Perú comprende varias clases de normas de acuerdo a una jerarquía. A la Constitución suceden las leyes y a éstas las disposiciones administrativas (Decretos $y^{\prime}$ Resoluciones). (79)

De acuerdo al procedimiento de formulación $y$ promulgación de las leyes previsto en el Título VI de la Constitución, las facultades legislativas corresponden al Congreso. El Poder Ejecutivo, sólo las re- glamenta "sin trasgredirlas ni desnaturalizarlas" (Art. 154), y puede dictar disposiciones administrativas.

Esta distribución de facultades se rompe generalmente durante los gobiernos de facto, ya que las facultades correspondientes al Poder Legislativo son asumidas por el Ejecutivo. (80)

Se han planteado diversos problemas en torno a las facultades legislativas de los gobiernos de facto y a la validez de los actos realizados por ellos, fundamentalmente en referencia a los gobiernos cuyo ac-

dispuesto que sea el Primer Ministro quien asuma algunas funciones del Presidente. Sin embargo, en la realidad la automía y la decisión de la Junta Revolucionaria no fue suficiente. Días después, el Decreto Ley No. 19443, refrendado por el Presidente de la República, disponia, con algunas variantes, medidas similares sujetas a un término.

Otro punto de interés en este sentido, es la duración de las funciones definidas en el Estatuto. Si bien los miembros de la Junta Revolucionaria la integran en tanto sean miembros activos de la Fuerza Armada, el Estatuto no prevé esta misma limitación para el Presidente y los Ministros.

De acuerdo con el art. 4o., los Ministros pueden ser milita. res o civiles, de manera que parece claro que la limitación anotada no rige en este caso. El Presidente de la República, on cambio, debe ser miembro de la Fuerza Armada al momento de su designación, no quedando claro qué debía suceder al pasar a retiro.

La práctica ha establecido que los Ministros al pasar at retiro, renuncien a su cartera (todos los Ministros de Estado hasta la fecha han sido miembros de la FF.AA.). Práctica inversa se ha dado en el caso de la Presidencia de la República. Cuando el Gral. Velasco en enero de 1969 pasó al retiro, fue ratificado como Presidente por la Junta Revolucionaria.

(78) GRAHAM HURTADO, José... Conferencia sustentada en la Cámara de Comercio Norteamericana del Perú. El texto ha sido tomado de: GARCIA BELAUNDE, Domingo: Aspectos recientes del constitucionalismo peruano (1966-1973), Lima, Editorial Rocarme, 1973; p. 9.

(79) Ver el interesante estudio al respecto de Dale B. Furnish: La Jerarquía del Ordenamiento Juridico Peruano. En: DERECHO, Lima, No. 30, 1972; pp. 61 a 80.

(80) Aunque constituye asunto distinto, debe tomarse en cuenta en un estudio de confrontación de la Constitución escrita con la real, el uso dela legislación delegada, figura que si bien está al margen de la Constitución, se ha usado en algunas oportunidades para que el Ejecutivo promulgue Decretos con fuerza de Ley, en virtud de una autorización del Parlamento durante gobiepnos de jure. 
ceso al poder significan un simple golpe de Estado. Aunque consideramos que el debate en torno a esta cuestión ha quedado ya ampliamente superado, queremos de todas maneras presentarlo, sobre todo en vista de que últimamente es el país esta problemática ha reaparecido en el debate público en torno a los problemas constitucionales antes señalados (supra 1).

Hoy se acepta en doctrina, incluso por los más renuentes a ello, que por razones de necesidad no se puede privar a la función de gobierno - sea ejercida por gobiernos de jure o de facto- de la facultad de legislar.

"Con referencia a la cuestión acerca de en qué grado las normas obligatorias originadas en el poder revolucionario son designadas como normas jurídicas... vemos la resistencia del sentimiento jurídico a que, de un simple poder, o incluso de una violación de derecho, si ésta ha tenido éxito, pueda emanar derecho... la necesidad práctica del derecho exige tener un orden jurídico obligatorio tan pronto como sea posible... Quizá la simple consideración con vistas a la práctica juridica diga que las exigencias, del orden y la seguridad jurídica, el Estado de necesidad político requieren que sea prestada obediencia a las disposiciones del nuevo poder; por esto dichas disposiciones son consideradas como normas jurídicas, aún cuando el sentimiento jurídico se resiste a ello" $(81)$

Sin embargo, a pesar de reconocerse la eficacia de los Decretos-Leyes de los gobiernos de facto, muchas veces se mantiene el cuestionamiento a su validez posterior, es decir cuando el gobierno defacto ha dejado el poder o cuando se restituye la validez del ordenamiento jurídico precedente.

En esta línea se da el cuestionamiento reciente del Dr. Bustamante y Rivero:

"2.- Pero frente a mis interpretaciones constitu-
cionales sobre el derecho de propiedad, el Dr.
Cornejo Chávez formula una observación de im-
portancia. El afirma, y es exacto, que la Consti-
tución no establece ella misma, en su propio
articulado; el régimen total de la propiedad:
sino sólo sus bases fundamentales: y que encar-
ga a "la ley", a las leyes ordinarias", la regula- ción de varias de las modalidades y limitaciones de ese derecho. Esto es precisamente, según sostiene el objetante, lo que ha ocurrido al promulgarse el nuevo Estatuto de la Prensa: el Gobierno Revolucionario está cumpliendo en encargo de la Constitución al regular mediante leyes los detalles del principio jurídico de la propiedad. Pero es el caso -a mi entender- que ese Estatuto emana de dos Decretos Leyes; y los Decretos Leyes no son "leyes ordinarias": no son "la ley" a que alude en ciertas ocasiones el articulado constitucional. Esta última "ley" es; sin que quepa duda; aquella cuyo proceso integral de formación; encargado a dos poderes del Estado, está previsto en el Título VI, arts. 124 y siguientes de la propia Carta. En cambio, cuando una revolución o una perturbación profunda en el régimen de gobierno (un receso parlamentario indefinido; por ejemplo) altera la normalidad constitucional, el "Decreto-Ley" viene a ser una forma legislativa extraconstitucional y de emergencia, un recurso transitorio de derecho consuetudinario que hace las veces de ley por razón de necesidad o fuerza mayor, para poder mantener en el exterior la personería internacional de la nación y en el interior para asegurar el funcionamiento ordinario de la vida del Estado, la provisión de sus finanzas y la subsistencia del orden. Por consiguiente, los Decretos Leyes representan instrumentos precarios de gobierno hasta tanto que la autoridad recupere su ejecutoria de legitimidad; medidas de salvamento dirigidas a preservar los elementos esenciales de la vida comunitaria mientras el pueblo decide libremente su destino final, Pero et Decreto-Ley no es estricto sensu, una ley plena y normal, pues le falta la emanación de la soberanía, la sanción de una voluntad popular legítima expresada a través de sus instituciones democráticas. Es este el elemento capital que presta a la norma legislativa su virtualidad de imperio. Prueba de ello es que, en múltiples ejemplos, una vez fenecida la etapa revolucionaria, los Decretos-Leyes son sometidos a revisión del nuevo Poder constituido y a su refrendación o su derogatoria si se descubre en algunos de ellos in-

(81) LINARES QUINTANA, Segundo...op. cit., T. VI, pp. $309-310$ 
conveniencia sustantiva, extralimitación de materia o abuso de poder. Todo lo dicho revela hasta qué punto resulta problemático y discutible en el terreno del razonamiento jurídico afirmar que los Decretos-Leyes pueden o deben prevalecer sobre el texto y el sentido del articulado de nuestra actual Constitución..." (82).

La doctrina se ha ocupado del tema en do: líneas distintas. La opinión del Dr. Bustamante SE inserta en términos generales en la primera de ellas. La tesis de la caducidad, postulada entre otros por Bielsa y Sánchez Viamonte, señala que, una vez res. tablecida la normalidad constitucional, caducan los Decretos-Leyes, los cuales sólo se han regido por la imposición de la fuerza, $y$ alcanzaron aceptación en vista de la necesidad de que la vida del Estado no se viera interrumpida. Por tanto, con el retorno al imperio de la Constitución, si es que el Congreso no otorga validez a tales Decretos Leyes, mediante su ratificación ellos caducan, quedando a salvo los derechos adquiridos bajo su imperio.

La objeción que se formula a este punto de vista, ha sido comúmente las de propiciar inseguridad juridica, sin embargo, sus defensores la han sostenido precisamente desde la defensa de la seguridad jurídica, ya que -argumentan- la igualación del Decreto-Ley con la Ley, llevaría no sólo a propiciar indirectamente la violación del ordenamiento juridico, sino a equiparar una disposición que generalmente responde a la voluntad de un grupo reducido de hombres que han usurpado el poder, con otra, fruto de un poder investido con representación democrática.

Una opinión extrema en esta línea es la postulada por Salvador Dana Montaño en la Argentina:

"...10. esos decretos-leyes no pueden ser convalidados ni ratificados. Si el Congreso estima conveniente que alguna norma contenida en ellos continuara en vigor, podría convertirla en ley, mediante el procedimiento ordinario, en cuyo caso ella tendría efectos desde su sanción, como una ley nueva. No podría darle efectos retroactivos .. 2o. que no es necesario tampoco que sean abrogados expresamente, porque caducan automáticamente, "ipso facto", por la terminación del gobierno que le dio vida"' $(83)$.
La otra vertiente en esta materia, es la de la continuidad de los Decretos Leyes, basada en su naturaleza legislativa $v$ en razones de seguridad jurídica. Esta tesis sostiene que los Decretos Leyes mantienen su vigor de ley, hasta que no sean derogados expresamente por el Congreso.

Para Enrique y Marcelo Aftalión no existe otra alternativa que la siguiente:

"O los Decretos Leyes tienen fuerza de leyes y valen como tales desde el momento en que han sido dicatos hasta tanto no sean derogados $y$ entonces la ratificación es superflua $o$, en cambio, siempre carecieron de validez, no siendo obligatorios ni siquiera bajo el gobierno de hecho que los dictó, hipótesis esta última inaceptable porque conduciría al caos...". (84).

En el caso de una revolución, este problema no parece trascendente. La sustitución de la base del ordenamiento jurídico, hará que los actos legislativos del gobierno revolucionario tengan una fuente de validez distinta a la del ordenamiento precedente. Una nueva norma base que da coherencia al sistema legislativo.

En cambio el problema sí parece tener algo más de interés en el caso de los golpes de Estado, en lo que no se da la sustitución del ordenamiento jurídico. Una somera revisión histórica puede ser de interés para ver las soluciones que se han dado en los diferentes casos.

En primer lugar, cabe anotar que solamente una vez se han puesto en funcionamiento los mecanismos constitucionales para sancionar como acto ilícito un golpe de Estado triunfante. En la realidad ha predominado una aceptación de la imposición fáctica de una gobierno al margen de los mecanismo

(82) Bustamante réplica a Cornejo. En: Caretas, No. 504 del 8 de octubre de 1975.

(83) DANA MONTAÑO, Salvador: La duración de los De. cretos-Leyes dictados por el gobierno provisional. En: La Ley, Buenos Aires, T. 90, 1958; p. 672.

En el Perú, al amparo de esta tesis podría invocarse el art. 19 de la Constitución: la nulidad de los actos de quienes usurpan funciones.

(84) AFTALION, Enrique y AFTALION, Marcelo... Los Decretos Leyes ante la Constitución real. En: La Loy, Buenos Aires, T. 114, 1964; p. 879. 
constitucionales. Constituyen situación excepcional las sanciones al régimen del General Cáceres aprobadas por el Parlamento posterior mediante ley del 20 de diciembre de 1845, la cual anuló la ley que pro. clamó Presidente a Cáceres y también declaró nulos sus actos gubernativos así como las leyes promulgadas durante su gobierno (85).

Las actitudes posteriores han sido diversas pero en ningún caso han reproducido una medida de esa naturaleza. Todo lo contrario. Entre las situaciones más recientes y sólo en referencia a la validez posterior de los Decretos-Leyes, tenemos que la Constituyente de 1931 mediante Ley No. 7476 nombró una Comisión para revisar los Decretos Leyes del gobierno de facto, la mayoría de los cuales fueron ratificados mediante leyes posteriores $(7477,7497,7501$, 7506, 7510 y 7513). La ley No. 7476 declaró asimismo, la insubsistencia de algunos Decretos Leyes que fueron dictados con posterioridad a la fecha señalada para su instalación. Esta declaración, sin embargo, no afectó Decretos-Leyes anteriores.

Las leyes dadas para ratificar Decretos-Leyes, utilizaron fórmulas diversas. En algunos casos "sancionan", to cual hace suponer que consideraron que nunca tuvieron verdadero vigor. En otras oportunidades declararan "subsistentes $v$ en todo su valor legal", lo que implica reconocer que sí lo tuvieron. En todo caso, es evidente que la Constituyente entendió que era necesario su pronunciamiento sobre la situación de los Decretos Leyes promulgados por el gobierno de facto.

En 1950 el Congreso instalado después de las elecciones, promulgó la Ley No. 11490 para ratificar los Decretos Leyes de la Junta de Gobierno, utilizando la fórmula de declarar que son Leyes de la República los Decretos Leyes 10889 a 11488.

En 1963, el Congreso nombró una Comisión Bicameral para el estudio de los Decretos Leyes promulgados por la Junta Militar de Gobierno de 1962. Como resultado de este estudio, se fue dando "fuerza de ley" a diversos Decretos Leyes.

Vemos que en el Perú el Congreso uniformemente ha considerado la necesidad de ratificar los Decretos-Leyes, pero es cierto que, Decretos Leyes que no fureron ratificados siguieron igualmente en vigor.
A nuestro entender esta ratificación no es otra cosa que la reiteración de su vigencia. No quita ni añada nada. Tan es así que cuando un Decreto Ley ha debido ser derogado, el Congreso de 1963 utilizó la palabra "deróguese" o "modifíquese", no pudiéndose derogar o modificar algo que no tenía fuerza de ley; es claro el reconocimiento implícito.

Para finalizar este acápite, queremos señalar que los Decretos-Leyes de los gobiernos de facto que significan sólo una interrupción de la vigencia plena de la Constitución, son el caso de úna mutación constitucional, ya que si bien la Constitución escrita, no reconoce sino una sola forma de generar la ley, podemos decir que en el Perú en la realidad, existen dos vías para dar leyes, una forma prevista en la Constitución escrita, que implica un procedimiento legal y otra excepcional, que opera en tiem. pos de gobiernos de facto, que pertenece a la constitución real y que es mediante Decretos-Leyes.

Los Decretos Leyes han funcionado y funcionan como leyes en la consideración de legisladores, magistrados, abogados y en la de la colectividad en general. Así pues la constitución real, integrada por fuentes consuetudinarias y jurisprudenciales equipara la Ley y el Decreto Ley, lo cual, conforme lo hemos señalado, constituye una mutación constitucional; los artículos pertinentes de la Constitución así como el art. I del T.P. del C.C., han cobrado en el mundo de las vigencias una realidad distinta a la normada, la cual es reconocida por la comunidad con poder normativo. Estamos pues ante una típica mutación constitucional que pone en práctica procedimientos distintos al texto de la Constitución escrita.

La constatación de esta situación, en función de lo afirmado en los acápites anteriores nos lleva -en el caso del golpe de Estado- a refrendar la opinión de Enrique y Marcelo Aftalión, que aunque formulada para el caso argentino, es aplicable también en nuestro país.

“. . la Carta Magna nada establece sobre la extraña situación que se produce cuando el Poder

(85) BASADRE, Jorge.. op. cit. T. VI; pp. 3017, 3018. CORNEJO, Mariano H... Discursos parlamentarios y politicos, T. II, po. 14 a 16. 
Ejecutivo es derrocado por vía revolucionaria y los nuevos gobernantes disuelven el Congreso, dejando subsistente, por lo demás, el Poder Judicial y admiten la validez general de la Constitución nacional. Esta situación no obstante se ha producido en los años 1930-43-55-62. El pa is entero vivió normalmente acatando las normas generales (Decretos-Leyes) promulgados por esos Gobiernos de facto, cosa que también hicieron los tribunales en sus fallos. De esta suerte puede decirse, sin lugar a dudas, que cualquiera sea la doctrina más o menos autorizada que pueda referirse a dicha situación evidentemente contraria a la Constitución legal, el régimen de los gobiernos de facto se fundamente en una constumbre general y constituye así toda una creación de nuestro Derecho constitucional consuetudinario". (86)

\subsubsection{La Jurisprudencia}

En el Perú, a diferencia de otros países, no existe lo que se conoce como una doctrina de facto (87), es decir un conjunto de principios elaborados jurisprudencialmente aplicables frente a la realidad de los gobiernos de facto a los cuales se les intenta dar un tratamiento jurídico. Solamente encontramos fallos judiciales dispersos en diferentes épocas, y una actitud bastante uniforme de los magistrados de no pronunciarse sobre el asunto de los gobiernos de facto (ver supra 1).

La jurisprudencia existente está fundamentalmente dirigida a resolver los efectos legales de los gobiernos de facto. La más antigua que hemos encontrado es respecto a la vigencia de los Decretos Leyes y abraza la teoría de la caducidad que, como vimos, pareció inspirar a los Constituyentes de 1931.

"No habiendo sido ratificado por el Congreso Constituyente el Decreto Ley No. 6983, la propiedad de tesoros hallados antes de la vigencia del nuevo Código Civil, está regida por las disposiciones del Código derogado". (88)

Luego nos encontramos con una Resolución de la Corte Suprema, resolviendo un Habeas Corpus planteado en 1949 contra la ley de Seguridad Interior. La jurisprudencia versa sobre facultades legisla- tivas de los gobıernos de facto, que es el tema sobre el cual más se ha pronunciado.

"... que dicho Decreto Ley tiene el mismo valor o eficacia que los otros decretos-leyes emanados de la misma fuente, al estar investida ia Junta Militar de Gobierno de funciones legislativas, única forma como un gobierno de facto puede dirigir la vida política, económica y jurídica del país...". (89)

Interesa en este mismo caso la opinión del Fiscal, Dr. Villegas, quien se pronunció en sentido diverso al de la Resolución.

“... pero no se justifica en manera alguna que la autoridad del Poder Ejecutivo, aún cuando no se tratara de un Gobierno de facto, sino de uno emanado del sufragio popular, se atribuya facultades que sólo al Congreso pertenecen máxime si se procede como en el Decreto-Ley No. 11049, desconociendo preceptos de la Carta Fundamental del Estado". (90)

En sentido contrapuesto fundamentó su voto el señor León y León, quien proclamó que la Constitución estaba en suspenso durante el gobierno de facto, mientras se normaliza el país. (91).

Con posterioridad, nos encontramos con una Resolución de la Corte Suprema del año 1965, también sobre vigencia de los Decretos Leyes.

"Los decretos leyes que expiden los gobiernos de hecho que asumen la función legislativa, rigen mientras no sean ratificados por el Congreso, o sean derogados, modificados o sustituídos por otra disposición legal semejante". (92).

(86) AFTALION, Enrique R. v Marcelo E. . op. cit., pp. 873-874.

(87) LINARES QUINTANA, Segundo... op. cit. pp. 452 v siguientes.

(88) En: GARCIA BELAUNDE. Domingo... El Constitu. cionalismo peruano y sus problemas, p. 4.1.8.2.h.

(89) HABEAS CORPUS - Ley de Seguridad Interior de la República. En: Rev. de Jurisp. Peruana, año 1950; p. 345. (90) Ibidem, p. 343.

(91) Ibidem, p. 347.

(92) En: GARCIA BELAUNDE, Domingo... El Constitucionalismo peruano $y$ sus problemas; $p$. 4.1.8.2.h. 
Aquí pues hay un criterio diverso al de 1938 y postula la Corte la continuidad de los DecretosLeyes que no hayan merecido la consideración del Congreso.

El reconocimiento de atribuciones legislativas a los gobiernos de facto, le encontramos también en la opinión vertida por el Dr. Domingo García Rada, como Presidente de la Suprema después del acceso at poder del Gobierno Revolucionario en 1968.

"En anteriores oportunidades el Tribunal Supremo ha aceptado como válidas las facultades legislativas de que se inviste una Junta de Gobierno. Conforme el artículo 6o. del Estatuto Revolucionario el Presidente de la República ejerce las atribuciones que. la Constitución otorga al Poder Ejecutivo y con el voto favorable del Consejo de Ministros, las del Poder Legislativo mediante Decretos Leyes... Estima la Sala que a todo gobierno de facto le es necesario hacer uso de las facultades que la Constitución confiere al Poder Legislativo, pues de lo contrario estaría imposibilitado de. realizar aquellos actos administrativos que conforme a la Constitución necesitan estar amparados por determinada. ley. Por otro lado, la intensidad de la vida moderna exige a diario la dación de nuevas normas de derecho destinadas a resolver situaciones antes no presentadas". (93)

A partir de 1968, nos vamos a detener en tres fallos en los cuales podemos encontrara la toma de una posición por parte del Poder Judicial sobre el problema que nos ha venido ocupando en este trabajo. Asimismo, cabe destacar que han sido durante este Gobierno tres los asuntos que predominantemente han motivado pronunciamientos en esta materia: Libertad de Prensa, Expropiaciones y Deporta. ciones; ello siempre ante Habeas Corpus presentados para la defensa de derechos constitucionales.

El primero es el recurso de Habeas Corpus presentado en 1968 por la Internacional Petroleum Company (IPC), contra los Decretos Leyes que expropiaron el complejo industrial de Talara $y$ anularon el Açta de Talara.

En el recurso se plantea la nulidad de los mencionados Decretos-Leyes, no porque tengan este carácter, sino parque en su contenido. se oponen a la 120
Constitución $y$, aplicando el Código Civil y la Ley Orgánica del Poder Judicial, se debe preferir el precepto constitucional cuando está en conflicto con otro de menor rango.

Según la I.P.C., se violó la Constitución porque los actos realizados implicaban la administración de justicia por un Poder distinto al que constitucionalmente está encargado; se trataria de una usurpación de funciones, $y$ por tanto los actos realizados son nulos en aplicación del art. 19 de la Constitución.

Con esta violación se alegan otras más. Nos interesa la que señala que también se ha violado lo dispuesto por el mismo Estatuto Revolucionario, ya que éste no confiere facultades judiciales al Poder Ejecutivo. La I.P.C. no objetó a los Decretos Leyes como verdaderas leyes y reconoció el Estatuto Revolucionario como fuente de derecho.

El pronunciamiento del Tribunal Correccional ofrece diversos puntos de interés:

“... que la multiplicidad de alegaciones formuladas por la International y los hechos invocados como actos violatorios de sus derechos, inciden y están sobordinados fundamental y esencialmente, a la expedición y vigencia de los referidos decretos leyes;... que sin embargo es evidente que los yacimientos fueron reinvindicados por la ley catorce mil seiscientos noventiseis, y que por la ley dieciseis mil seiscientos cincuenticuatro, dictada por el último Congreso de la República, se señaló al Poder Ejecutivo el mejor camino a seguir, no sólo el más conveniente para el interés nacional, sino el más favorable, por lo que la Junta Militar a mérito de sus Decretos Leyes Números tres y cuatro, puso término al régimen de privilegio, anulando los contratos de agosto y setiembre último, expropiando y tomando posesión del Complejo Industrial de Talara y las instalaciones de Verdum Alto, con sus anexos y accesorios; que debe tenerse muy en cuenta que para esto la Fuerza Armada, no actuó de motu-propio, sino que previamente asumió el mando de la Nacion avocándose en la práctica los Poderes Legislativo y Ejecutivo, bajo un rígido Estatuto inmodifica-

(93) GARCIA RADA, Domingo... op. cit;; p. 7. 
ble, en el que, promete actuar conforme a la Constitución del Estado e imprimir a sus actos un sentido eminentemente nacionalista (*)... que la Junta Militar Revolucionario recogiendo el anhelo unánime de la ciudadanía, al dictar los Decretos Leyes que se pretenden impugnar y al ocupar el complejo industrial, se ha ceñido al mandato de la ley dieciseis mil seiscientos setenticuatro, hay que concluir que lo ha hecho en pleno ejercicio de la soberanía nacional, por lo que no sólo no cabia la investigación derivada del Recurso de Habeas Corpus ... sino que este mismo recurso es inadmisible; que dentro del actual ordenamiento legal vigente no hay disposición constitucional que permita al Tribunal Correccional declarar la incostitucionalidad de los Decretos Leyes; que es verdad que el artículo veintidos del título preliminar del Código Civil dispone que cuando hay incompatibilidad entre una disposición constitucional y una legal, se prefiere la primera; y que el artículo octavo de la ley orgánica del Poder Judicial establece que cuando los jueces y tribunales encuentren que hay incompatibilidad entre las referidas disposiciones, se prefiere la constitucional; pero no faculta a declarar la anticonstitucionalidad de la Ley o Decreto Ley ... ".. (94)

La Corte Suprema ratificó esta sentencia, señalando entre los considerandos que los DecretosLeyes en cuestión han sido expedidos "en ejercicio de las funciones establecidas en el artículo sexto del" Decreto-Ley número diecisiete mil sesentitrés" (Estatuto Revolucionario). Y el Fiscal en su informe señaló que:

"El Gobierno Revolucionario de la Fuerza Armada, al tomar el mando asumió también las funciones de los Poderes Legislativos y Ejecutivo, por consiguiente, las disposiciones emanadas de aquél tienen carácter de leyes del Estado; es obvio que en este caso el Poder Judicial carece de facultades para declarar la nulidad de las mismas, debiendo actuar con estricta sujeción a lo que disponen los artículo XXII del Título Preliminar del C.C. y 8o. de la L.O. del P.J." (95)

Algunos aspectos debemos destacar. Primero, tanto la Corte como el Tribunal y el demandante equiparan el Decreto Ley a la Ley, no habiendo ningún cuestionamiento sobre el particular. En base a esa equiparidad es que la Corte resolverá que no tiene facultades para declarar la inconstitucionalidad de las leyes, y por tanto tampoco de los DecretosLeyes. De esta manera queda claro, una vez más, la aceptación en la constitución real de los decretos leyes como otra modalidad de ley.

En la sentencia del Tribunal hay un evidente reconocimiento del gobierno de facto, $y$ de esa modalidad de acceso al poder, cuando se refiere a que "la Fuerza Armada no actuó de motu-propio, sino que previamente asumió el mando". Se reconoce la actuación del Gobierno Revolucionario en base a un hecho: la asunción del mando por la fuerza.

Tanto el Tribunal como la Corte admiten el Estatuto Revolucionaro como fuente legislativa. El Trisbunal parece fundar este reconocimiento en una premisa que consideramos inexacta: al asumir el gobierno por la fuerza y al promulgar su Estatuto, el gobierno no prometió actuar conforme a la Constitución, como se afirma. Como hemos visto se trata precisamente de lo contrario, ya que el Estatuto sujeta a ésta a los fines que él enumera atribuyéndole un rol supletorio. Lo cual, es evidente, la Corte y el Tribunal de entonces se negaran a admitir.

Sin embargo en estas decisiones judiciales, hay algo más que la simple negativa a declarar la nulidad de decretos leyes, nos parece que existe un reconocimiento al gobierno de facto, $y$ conretamente a su norma base, así como de. los efectos legales que estos gobiernos producen, aunque ciertamente el golpe de Estado, lo que nos permite reiterar en la aceptación usual de este fenómeno, y en la implantación de vigencias opuestas a la Constitución.

Otro fallo reciente que nos interesa, es el emitido en 1969 en una acción de Habeas Corpus contra el Decreto Ley No. 18017 dejó en suspenso las elecciones municipales.

Dice el Juez de Primera Instancia:

“A) Que es una realidad innegable que el actual 94) Diario oficial "El Peruano", 12 de noviembre de 1968 Exp. 969-68.

95) Loc. cit.

(*) El subrayado es nuestro. 
gobierno, por efecto de su Estatuto Revolucionario, de fecha tres de octubre de mil novecientos sesentiocho, asumió las facultades legislativas; B) Que en tal virtud con acatamiento de los gobernados ejercita constantemente su función legiferante de acuerdo a sus fines y a las necesidades públicas; C) Que si bien es discutible en doctrina la validez de esa arrogación, es también reconocida la necesidad que el Gobierno provoca a su ejercicio en las circunstancias presentes; ...". (96)

En esta primera parte del fallo del Juez de Primera Instancia, tenemos que se limita a efectuar constataciones de hecho en los dos primeros acápites, $y$ en el tercero a señalar que ante ellos, es reconocida por razón de necesidad de que el Gobierno ejercite la función legiferante. La referencia al Estatuto es muy cautelosa; se hace simplemente para constatar que en virtud de tal, se ejerce la función legislativa, la cual se juzga necesaria.

En su segunda parte, el Juez de Primera Instancia relaciona la coyuntura que se vive con la realidad del gobierno de facto y el Poder Judicial.

“...D) Que en esta coyuntura asi como es una exigencia que el Poder Judicial preserve la vigencia del orden constitucional dando amparo a todo caso de transgresión de los derechos individuales y sociales inherentes a la persona humana, corresponde en salvaguarda de su misma independencia rechazar toda pretensión encauzada a la definicón judicial sobre prevalencias de derechos o instituciones de contenido o carácter político ....". (97)

Es decir de acuerdo al criterio señalado, el Poder Judicial puede amparar derechos individuales $Y$ sociales, pero por una razón de subsistencia no puede declarar derechos o instituciones de carácter político; no es que no sea función del Poder Judicial, sino que "en esta coyuntura" y en "salvaguardia de su independencia", no puede declarar tales derechos.

Finalmente, el Juez decide que por versar la demanda precisamente sobre estos derechos, es improcedente $y$ además porque la Acción Popular se puede esgrimir sólo en contra de resoluciones $y$ de- cretos gubernativos del Ejecutivo, y ésta es una ley, equiparando así nuevamente la ley con el decreto ley, cosa que hoy como se ve no admite discusión.

“... siendo evidente que la norma impugnada es de otra naturaleza, pues al ratificar la suspensión de los efectos de una ley y regular la provisión y actuación de los Concejos Municipales, es obvio que concierne el uso de una facultad legislativa; G) Que esta última consideración se desprende también de la formalidad con que se dio y publicó el propio Decreto-Ley, conforme a lo preceptado por tal hipótesis por el art. 6o. del precitado Estatuto”. (98)

Por último queremos resaltar una sentencia que se ocupa de los problemas que venimos analizando en una forma harto distinta a las anteriores. Abandonando las preocupaciones que encontrábamos en las otras, determina en una forma muy directa que el art. 5o. del Estatuto Revolucionario da validez a las acciones del Gobierno encaminadas a lograr la transformación de las estructuras en el Perú. Lo que hace el Tribunal en este caso, además de pronunciarse claramente sobre la revolución como fuente de derecho, es prácticamente limitarse a analizar si la acción realizada tiene o no justificación desde la óptica del cumplimiento de los fines de la revolución.

Se trata de la sentencia que recayó en el Habeas Corpus interpuesto en setiembre de 1973, cuando se impidió el ingreso al país del señor Raimundo Duharte, Presidente de la Sociedad de Industrias.

"Lima, enero ocho de mil novecientos setenticuatro.- Autos y vistos; oído el informe oral y considerando: que a fojas treintiuna, doña Gladys Fernández Cornejo de Duharte, invocando lo estatuído en los artículos sesentisiete, sesentiocho, y sesentinueve de la Declaración de los Derechos Humanos y trescientos cuarentinueve y trescientos cincuentiuno del Cógido de Procedimientos Penales, y el mérito de los recaudos insertos de fojas tres a fojas treinta interpone

(96) Archivo. Dr. Domingo García Belaúnde. mingo García Belaunde.

(97) Loc. cit.

(98) Loc. cit. 
recurso de habeas corpus, en favor de su esposo, Raymundo Duharte Castre, a quien el dieciséis de noviembre de mil novecientos setentitrés se le impidió proseguir el vuelo número setecientos setenticinco de la Linea KLM iniciado en la ciudad de Caracas con destino a Lima, hecho admitido por el Señor Ministro del Interior, General Ejército Peruano Pedro Richter Prada, justificando la medida adoptada en las actividades del citado Duharte, contrarias al espíritu y letra del Estatuto del Gobierno Revolucionario, cuya obra innegablemente concita el respeto y reconocimiento de valiosos sectores de la ciudadanía, porque a nadie escapa en estos momentos tan significativos de la Historia $\mathrm{Na}$ cional, los profundos cambios de que es objeto la sociedad peruana, en sus diversos aspectos; tarea que supone no sólo la creación de una estructura material y técnica adecuada a la promoción del país, sino también la formación de una mentalidad ciudadana que al estimulo de los valores encarnados en los símbolos patrios induzca a sumar esfuerzos en la concresión de los fines trazados por la sociedad; que ese importante cometido requiere igualmente de un ordenamiento jurídico concebido e interpretado sin desvincularlo de las exigencias impuestas por las necesidades sociales del presente, las mismas que. se hallan resumidas en los fines explicados y enunciados en los artículos primero y segundo del decreto ley diecisiete mil sesentitrés de tres de octubre de mil novecientos sesentiocho y que en lo que atañe al Poder Judicial, constituyen los criterios rectores que debe inspirar su positiva contribución al proceso que "reclama el bienestar del pueblo peruano y el desarrollo del país", nuevo enfoque que revela con comprensible claridad que el artículo quinto del Estatuto del Gobierno Revolucionario no es incompatible con la Constitución del Estado, sino que es el punto de entroncamiento entre ambas normas legales, desprendiéndose, como consecuencia que las garantias individuales $y$ sociales adquieran sentido y dinamismo en la medida en que los actos por ellas protegidos guardan armonía con los objetivos nacionales que en la hora actual, es obvio recalcarlo, genera a cada ciudadano es,pecíficos deberes y la oportunidad de elegir entre dos sistemas sustancialmente excluyentes en cuanto a sus motivaciones y finalidades: uno, que ineludiblemente condujo a la Nación a la dependencia económica, cultural e internacional y otra, tendiente a superar esa anómala situación propendiendo a formar una sociedad caracterizada por un superior nivel de vida, la integración de los peruanos y el fortalecimiento de la soberania y dignidad nacionales; que de otro lado, el mencionado decreto ley, surgido de trascendetales acontecimientos históricos enaltecidos por sus proyecciones nacionalistas soberanas $y$ humanistas, ha dado lugar a numerosos dispostivos legales dirigidos a reordenar las funciones públicas y las variadas expresiones del esfuerzo privado, normas que son acatadas y aplicadas cotidianamente por los órganos administrativos y jurisdiccionales, de modo que tampoco es admisible se cuestione su legalidad y vigencia; que al calificarse la conducta de Duharte Castre de contraria al espiritu y letra del Estatuto del Gobierno Revolucionario, tenemos que inferir que se ha estimado su actuación como opuesta a los principios, postulados y fines de la nueva orientación que se está imprimiendo al pais en sus realizaciones internas y exteriores: declararon infundado el recurso de habeas corpus interpuesto a fojas treintiuna por Gladys Fernández Cornejo de Duharte, a favor de Raymundo Duharte Castre contra el señor Ministro del Interior, General Pedro Richter Prada; ordenaron su archivamiento definitivo, Freyre Villavicencio - Mantero Fetzer - Romar Arana - Secretario - Pedro Romero" (99).

Ciertamente esta sentencia va bastante lejos, es el reconocimiento de un campo libre de acción al Gobierno Revolucionario, en función del cumplimiento de los objetivos de éste. Han habido cambios de criterios en Poder Judicial; desde aquellas declaraciones de "neutralidad" en las Memorias, o desde aquellas sentencias preocupadas en la validez de los decretos leyes, se ha llegado recientemente a declaraciones como la que hemos transcrito. $Y$ es que, sin duda, las medidas de reorganización del Po-

(99) Diario "La Prensa", 10 de enero de 1974. 
der Judicial que median entre aquellas y ésta han producido algunos cambios de actitud. Lamentablemente la Corte Suprema de la República, a pesar de que tuvo en consideración muchos meses estr. caso, no llegó a pronunciarse sobre él, ya que hubiera sido interesante conocer cuan difundido estaba este criterio en nuestro Poder Judicial.

Al concluir, queremos reiterar la importancia de plantear el estudio del Derecho Constitucional en confrontación con la realidad. Por ello creemos fundamental no perder de vista las vigencias constitucionales y el fenómeno de las mutaciones. En este contexto, hemos planteado un problema, el de los gobiernos de facto, acerca del cual reiteramos el interés que reviste el estudio de este fenómeno desde el punto de vista jurídico, para lo que es menester dejar de lado una posición formalista que hasta ahora ha primado, y que ha conducido a excluirlo del ámbito del estudio del Derecho.

Consideramos, que el Derecho Constitucional peruano no puede seguirse centrando en una exégesis del texto constitucional. No puede nutrirse más de una visión estancada en instituciones teóricamente perfectas, en principios valiosos en sí mismos. Es menester estudiar el derecho en funcionamiento, volver los ojos a la realidad constitucional, usar del aporte de otras ciencias que tienen que ver con el ordenamiento de la vida del Estado. Hay que "desacralizar" el Derecho Constitucional, y estudiarlo dentro del contexto histórico, social y económico, sin proclamar principios absolutos, prestando atención a las vigencias y a la realidad constitucional.

Lima, octubre de 1974 